\title{
Review \\ The Bibliometric Analysis and Review of the Application of Plasma in the Field of VOCs
}

\author{
Yi Xing ${ }^{1,2}$, Wenbo Zhang ${ }^{1}$, Wei Su ${ }^{1,3, *}$, Hui Zhang ${ }^{1}$, Jiaqing Wang ${ }^{1}$, Hongshuo Zhang ${ }^{1}$, Zefeng Guo ${ }^{1}$ \\ and Haoqi Jia ${ }^{4}$
}

check for

updates

Citation: Xing, Y.; Zhang, W.; Su, W.; Zhang, H.; Wang, J.; Zhang, H.; Guo, Z.; Jia, H. The Bibliometric Analysis and Review of the Application of Plasma in the Field of VOCs. Catalysts 2022, 12, 173. https:// doi.org/10.3390/catal12020173

Academic Editor:

Annemie Bogaerts

Received: 29 December 2021

Accepted: 27 January 2022

Published: 28 January 2022

Publisher's Note: MDPI stays neutral with regard to jurisdictional claims in published maps and institutional affiliations.

Copyright: (C) 2022 by the authors. Licensee MDPI, Basel, Switzerland. This article is an open access article distributed under the terms and conditions of the Creative Commons Attribution (CC BY) license (https:// creativecommons.org/licenses/by/ $4.0 /)$.
1 School of Energy and Environmental Engineering, University of Science and Technology Beijing, Beijing 100083, China; xingyi@ustb.edu.cn (Y.X.); b20190071@xs.ustb.edu.cn (W.Z.); g20198239@xs.ustb.edu.cn (H.Z.); b20200082@xs.ustb.edu.cn (J.W.); 19801283650@126.com (H.Z.); a214531935@163.com (Z.G.)

2 Beijing Key Laboratory of Resource-oriented Treatment of Industrial Pollutants, University of Science and Technology Beijing, Beijing 100083, China

3 Key Laboratory of Knowledge Automation for Industrial Processes, Ministry of Education, Beijing 100083, China

4 College of Environmental \& Resource Sciences of Shanxi University, Taiyuan 030006, China; jhq18756022205@126.com

* Correspondence: suwei@ustb.edu.cn; Tel.: +86-010-6233-3434

\begin{abstract}
The application of plasma in the field of volatile organic compounds (VOCs) can be traced back to the 1990s and has gradually developed into an important research field. In this regard, this article primarily sorts and analyzes the literature on the "application of plasma in the field of VOCs" in the Web of Science core collection database from 1992 to 2021 and, subsequently, obtains important data and trends, including the annual number of articles published, country, institution analysis, and journal, as well as discipline analysis, etc. The results show that China is not only in a leading position in the field of research, but also has six top-ten research institutions. This field has more research results in engineering, chemistry, physics, and environmental disciplines. In addition, this article summarizes dielectric barrier discharge (DBD) and titanium-containing catalysts, which represent the discharge characteristics and type of catalyst highlighted through the hot keywords. This review will provide certain guidance for future, related research.
\end{abstract}

Keywords: plasma; bibliometric; titanium-containing catalyst; dielectric barrier discharge

\section{Introduction}

As a common air pollutant, volatile organic compounds (VOCs) are widely derived from the processing and production processes of various industries, such as the exhaust emissions in the production process of petrochemical products, waste incineration flue gas emissions, and processing gas emissions from steel coking production. As a series of harmful pollutants, they (VOCs) include alkanes, alkenes, alcohols, ketones, aldehydes, aliphatic hydrocarbons, aromatic hydrocarbons, chlorinated organic pollutants, sulfurized organic pollutants, and nitrogenous organic pollutants, etc. [1], which are very harmful to the ecological environment. Commonly, VOCs will consume ozone in the atmosphere, destroy the ozone layer, and cause phenomena such as photochemical smog and urban haze. In addition, VOCs are harmful to the ecological environment and cause great harm to human health. Long-term exposure of the human body to certain VOCs will cause various incurable and irreversible diseases, such as cancer, various respiratory diseases, skin diseases, and so on [2]. In the context of the era of large VOCs emissions, from 1970 to the present, the world has held many conferences, concluding, as well as promulgating, extensive, related agreements, laws, and regulations, including the "Clean Air Act" promulgated by the United States in 1970, which required $70 \%$ of pollutant emission reductions to be achieved by 2000; the "Gothenburg Protocol", which required member states to reduce 
emissions of pollutants by half of that in 2000 by 2020 [3]; the "Stockholm Convention", which entered into force in 2004 and also aims to strengthen the management of chemicals and reduce the harm caused by chemicals, especially toxic and hazardous chemicals [4]. Therefore, the problems caused by controlling and reducing VOCs emissions have become the responsibility of all countries in the world.

The research on plasma dates back to 1705 when Francis Hauksbee was charged and discharged under vacuum for the first time [5]. This was the beginning of plasma research. In the 1830s, Faraday and others began to study the phenomenon of gas discharge. In 1857, Siemens and others studied the generation of ozone from atmospheric oxygen discharge [6]. By 1879, Crooks and others in the United Kingdom used a fourth state other than liquid, solid, or gas to describe the ionized gas in the gas discharge vessel [7]. In 1928, American scientists Irving Langmuir and Tonks introduced the term "plasma" into physics for the first time to describe the form of matter in a gas discharge tube. As a result, plasma emerged in the form of a physics term. Plasma is an ionized gas which is composed of some generated positive and negative ions after the electrons have been deprived of atoms and the ionization of atomic groups. The movement of macroscopically neutral ionized gas with a scale larger than the Debye length is mainly dominated by electromagnetic force and exhibits significant collective behavior. Plasma can decompose gas into various, high-speed, charged particles, including electrons, molecules, atoms, active radical groups, etc. It can also excite the gas to generate metastable and excited molecules, atoms, and active radical groups [8,9]. Distinguished by the reaction temperature, plasma is divided into high-temperature plasma (thermal plasma) and low-temperature plasma (non-thermal plasma or cold plasma); the apparent reaction temperature of the former can reach $20,000^{\circ} \mathrm{C}$ or even higher, and it has the advantages of high temperature, high intensity, high energy density, and non-ionizing radiation. The apparent reaction temperature of the latter only reaches room temperature or slightly higher than room temperature. Its advantages are low apparent temperature, high electron energy, low energy consumption, and high efficiency. The application of plasma in the field of VOCs mainly includes VOC degradation, by-product control and resource utilization [10,11], high-sensitivity detection [12,13], etc. In related research, the number of reports on the degradation of VOCs is the largest, and it is also the most popular based on the international environment. For a long time, scholars in many countries have been working on the degradation technology of VOCs. VOC degradation technologies include the adsorption method, condensation method, membrane separation method, biochemical method, direct combustion method, catalytic combustion method, plasma oxidation, and plasma catalysis [14-22], etc. Plasma technology has been widely favored by scholars from various countries in recent years due to its high efficiency, high cost performance, and low energy consumption, which indicates that low-temperature plasma technology is a promising technology.

The statistical method based on bibliometrics has a wide range of applications in many disciplines and fields. The purpose of this research is to analyze and organize the data obtained using bibliometric statistical methods, including a comprehensive analysis of the number of articles, author country, author institution, journal subject distribution, author keywords, etc. This article analyzes, organizes, and summarizes the article data on the "application of plasma in the field of VOCs" in the Web of Science core collection database from 1992 to 2021 (the term first appeared in this field in 1992) and summarizes the hot content of "application of plasma in the field of VOCs".

\section{Data Sources and Methodology}

The statistical data of the article were mainly derived from the Science Citation Index Expanded (SCI-EXPANDED) citation index of the Web of Science core collection database. The data collection date was 28 June 2021, and the subject heading was composed of two parts: $A$ and $B$, in which $A$ represents the expression forms of plasma in the literature, including: "plasma", while B stands for volatile organic compounds in different expressions in the literature, including "VOCs" or "VOC" or "Volatile Organic Compounds" or "Volatile 
Organic Compound". The article makes a statistical analysis of all relevant document types, countries, affiliated institutions, keywords, authors, and subject classifications in the core database of Web of Science from 1901 to 2021. In this measurement analysis, Microsoft Office 2016, Origin 2021, ESRI ArcGIS 10.2, etc., were used for data processing, retrieval, analysis, and drawing [23-27].

\section{Results and Discussion}

According to the bibliometric analysis data, in the Science Citation Index Expanded (SCI-EXPANDED) citation index of the Web of Science core collection database, a total of 1501 articles about "application of plasma in the field of VOCs" from 1 January 1992 [28] to 28 June 2021 were included. This article only systematically analyzes 1181 academic papers from 1997 to 2021 (nearly twenty-five years) in terms of the number and trends of articles, country and institution analysis, journal and discipline analysis, and hot keywords. At the same time, several typical keywords with high frequency are systematically reviewed.

\subsection{Number of Articles and Trend Analysis}

Generally speaking, the number of articles in a field is an important indicator to evaluate the development trend, current situation, and prospects of related fields. Figure 1a shows the number of academic articles on "application of plasma in the field of VOCs" from 1992 to 2021; Figure 1b shows the total number of publications of "plasma applications in the field of VOCs" from 1992 to 2021. It can be seen from Figure 1 that the related literature on "application of plasma in the field of VOCs" began to appear in 1992. However, in the seven years from 1992 to 1998, the number of articles in this field was relatively small, indicating that the development of this field was relatively slow and had a lack of creative breakthroughs in the first few years. Since 1999, the number of academic articles increased significantly, nearly twice that of the first few years; this may be attributed to the plasma technology which began to make breakthroughs in 1999. It is worth mentioning that the number of articles in this field reached the maximum in 2020 (117 articles), which may be due to the decrease in people's daily activities during the new coronavirus epidemic in 2020 and researchers devoting more time to scientific research. The red, dotted line in Figure 1 shows the trend of academic articles and total publication volume of "application of plasma in the field of VOCs" from 1992 to 2021; it can be seen that, although the academic articles and the total publication volume of plasma applications in the field of VOCs show volatility, the overall trend is increasing. Additionally, the upward trend is more obvious since 1999, which shows that the field of "application of plasma in the field of VOCs" is in the rising period of research, and it is also a current research hotspot. Scholars are becoming more and more interested in this field.
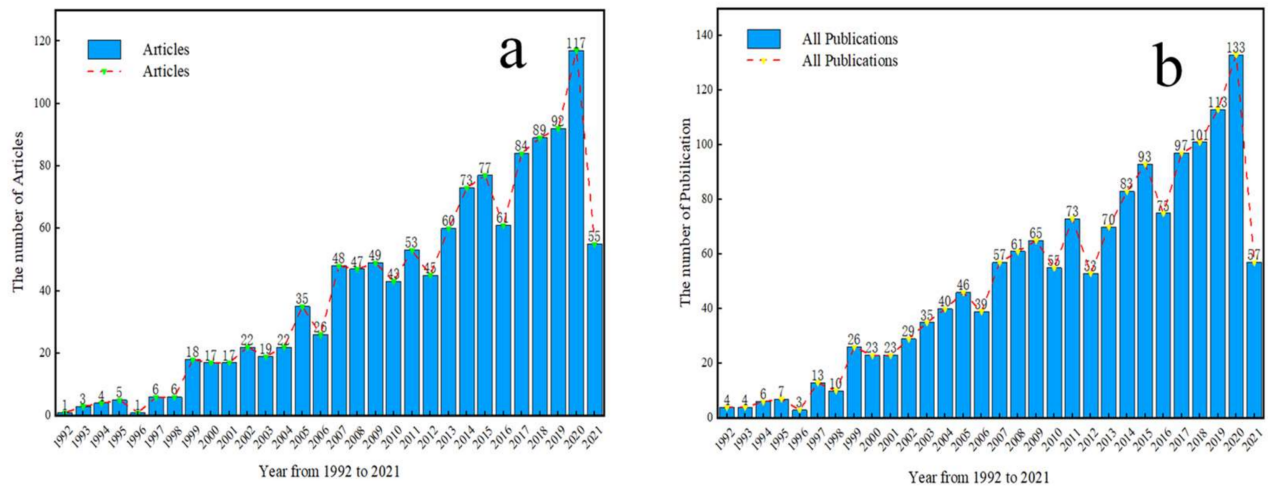

Figure 1. The number of academic articles on the application of plasma in the field of VOCs (a) and the total number of publications (b) from 1992 to 2021. 


\subsection{National and Institutional Contributions}

Generally, data analysis of countries/regions is capable of determining which countries/regions have higher influence and the best research foundation in this field. Among them, academic articles from mainland China, Hong Kong, Macau, and Taiwan are all classified as "China"; academic articles from England, Scotland, Northern Ireland, and Wales are all classified as "United Kingdom". After re-categorizing, among the 1181 academic papers in the past fifteen years, 69 countries were involved, the number of papers published in a single country/region was 1004, accounting for $85.01 \%$, and the number of papers published in cooperating countries/regions was 177 , accounting for $14.99 \%$. Table 1 shows the top 10 productive countries from 1997 to 2021; it can be seen that China's number of posts in this field ranks first, with 424 posts, accounting for $29.8 \%$; the United States is in second place, with 145 articles, accounting for 10.2\%; France is in third place, with 111 articles, accounting for 7.8\%; and Japan and South Korea are in fourth and fifth places, with 93 and 85 articles. Although both the United States and France have posted more than 100 articles, there is a big difference in the number of articles issued compared with China. The total number of articles issued by China in this field is almost equal to the total number of articles issued by the United States, France, Japan, and South Korea.

Table 1. Top 10 productive countries from 1997 to 2021.

\begin{tabular}{cccc}
\hline Rank & Country & TP & TP R (\%) \\
\hline 1 & China & 424 & $29.8 \%$ \\
2 & USA & 145 & $10.2 \%$ \\
3 & France & 111 & $7.8 \%$ \\
4 & Japan & 93 & $6.5 \%$ \\
5 & South Korea & 85 & $6.0 \%$ \\
6 & Germany & 67 & $4.7 \%$ \\
7 & UK & 47 & $3.3 \%$ \\
8 & Italy & 38 & $2.7 \%$ \\
9 & Poland & 35 & $2.5 \%$ \\
10 & Belgium & 33 & $2.3 \%$ \\
\hline
\end{tabular}

Note: TP is the number of total publications: TP R (\%) is the ratio of the number of one journal's publications to the total number of publications.

In order to vividly show the contributions of countries and continents in the field, ESRI ArcGIS 10.2 geographic information system software was used to sort out the number of articles issued by various countries, and the results are shown in Figure 2. Figure 2 presents the distribution of the number of articles published by various countries in the world from 1997 to 2021. The different shades of color in the picture represent the number of articles issued by different countries in this field. The darker the color, the more articles published. In the figure, it can be clearly seen that the articles in this field are mainly concentrated in China, the United States, and France. At the same time, Japan, South Korea, Germany, and other countries are also prominent in this field. In addition, countries in Europe and North America have extensive research in this field; Africa, South America, and Asia have relatively poor participation in research in this field, and only China has a large proportion of them.

Generally speaking, the data analysis of different research institutions can well show the research level in this field. Through analysis, in the fifteen years from 1997 to 2021, a total of 1036 institutions published 1181 academic papers. Table 2 shows the data analysis of the top 10 institutions in terms of publication volume. Among the top ten institutions, there are six institutions distributed in China and one each in Japan, Belgium, the United Kingdom, and France. This illustrates China's leading position in this field. Zhejiang University ranked first, with 49 articles, accounting for $4.1 \%$; Dalian University of Technology ranked second, with 40 articles published, accounting for $3.4 \%$; third place is the Japanese organization National Institute Advanced Industrial Science and Technology, with 22 articles (1.9\%); the Chinese Academy Sciences of China and Ghent University of Belgium 
ranked fourth and fifth, with 22 articles (1.9\%) and 17 articles (1.4\%), respectively; the organizations ranked sixth to tenth issued fewer articles, but the number of articles published was relatively average, with the number of each being around 15. Zhejiang University, which ranks number one, has a wide range of research content in this field, including plasma combined with catalysis and synergistic degradation of conventional VOCs [29,30] and malodorous gases [31], as well as the recycling of pollutants [10] and the control of harmful by-products [11]. Some scholars also carried out related simulation work [32]. Dalian University of Technology, ranked second, mainly studied the degradation of VOCs by low-temperature plasma synergistic catalysts in this field [33-36]; the National Institute Advanced Industrial Science and Technology and Chinese Academy Sciences, ranked third and fourth, have done a lot of work on the plasma catalytic degradation of VOCs, as well as high-sensitivity VOC gas sensors $[12,13,37,38]$.

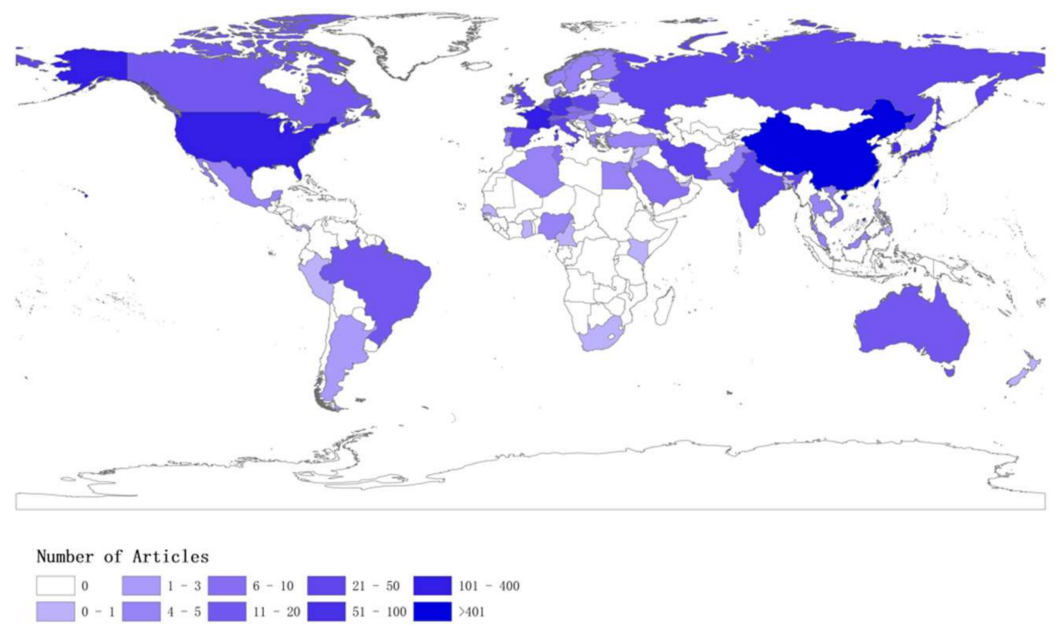

Figure 2. Geographical distribution of articles, 1997-2021.

Table 2. Top 10 productive institutions from 1997 to 2021.

\begin{tabular}{cccccccc}
\hline Rank & Institution & TI & TI R (\%) & SI R (\%) & CI R (\%) & FI R (\%) & RI R (\%) \\
\hline 1 & Zhejiang University, China & 49 & $1(4.1)$ & $1(5.1)$ & $4(2.1)$ & $1(3.9)$ & $1(3.8)$ \\
2 & Dalian University of Technology, China & 40 & $2(3.4)$ & $2(3.1)$ & $1(4.0)$ & $2(2.6)$ & $2(2.6)$ \\
3 & National Institute Advanced Industrial & 22 & $3(1.9)$ & $3(1.9)$ & $6(1.8)$ & $3(1.5)$ & $3(1.5)$ \\
4 & Science and Technology, Japan & & & & & \\
4 & Chinese Academy Sciences, China & 22 & $3(1.9)$ & $5(1.2)$ & $2(3.2)$ & $5(1.3)$ & $4(1.4)$ \\
5 & Ghent University, Belgium & 17 & $5(1.4)$ & $5(1.2)$ & $6(1.8)$ & $6(1.1)$ & $7(1.0)$ \\
6 & University of Manchester, UK & 16 & $6(1.4)$ & $5(1.2)$ & $11(1.6)$ & $6(1.1)$ & $7(1.0)$ \\
7 & Shanghai Jiao Tong University, China & 16 & $6(1.4)$ & $4(1.7)$ & $87(0.5)$ & $4(1.4)$ & $4(1.4)$ \\
8 & University Paris 11, France & 14 & $8(1.2)$ & $5(1.2)$ & $27(1.1)$ & $10(0.9)$ & $12(0.8)$ \\
9 & Sichuan University, China & 14 & $8(1.2)$ & $11(1.1)$ & $15(1.3)$ & $8(1.0)$ & $6(1.1)$ \\
10 & South China University of Technology, China & 14 & $8(1.2)$ & $5(1.2)$ & $27(1.1)$ & $8(1.0)$ & $7(1.0)$ \\
\hline
\end{tabular}

Note: TI is the number of total publications in a certain institution; TI R (\%) is the ratio of the number of one institution's publications to the total number of publications; SI R (\%) is the ratio of the number of one single institution's publications to the total number of all single institutions' publications; CI R (\%) is the ratio of the number of one cooperate institution's publications to the total number of all cooperate institutions' publications; FI $\mathrm{R}(\%)$ is the ratio of the number of one institution's publications to the total number of all institutions' publications (the institution is where the first author is located); RI R (\%) is the ratio of the number of one institution's publications to the total number of all institutions' publications (the institution is where the correspondence author is located).

\subsection{Journal and Subject Distribution}

Through the analysis and sorting of 1181 academic papers in this field searched in the Web of Science, it was also easy to obtain key information about different journals in this field. Table 3 shows the top ten journals in terms of publication volume during the 
fifteen years from 1997 to 2021. These include total publications, the ratio of one journal's publications to the total publications, total citations, citations per publication, impact factor in 2021, and H-index. The journal with the most publications in this field is PLASMA CHEMISTRY AND PLASMA PROCESSING, with 77 publications, accounting for $6.5 \%$. The second-ranked journal is CHEMICAL ENGINEERING JOURNAL, with 62 articles (5.2\%). The journals ranked third and fourth are JOURNAL OF HAZARDOUS MATERIALS and APPLIED CATALYSIS B-ENVIRONMENTAL, with a volume of approximately 40 articles each; 44 (3.7\%) and 42 (3.6\%), respectively. The fifth and sixth journals are JOURNAL OF PHYSICS D-APPLIED PHYSICS and IEEE TRANSACTIONS ON PLASMA SCIENCE, with $34(2.9 \%)$ and $26(2.2 \%)$ publications, respectively. The remaining journals have published fewer than 20 articles. Among the top ten journals in terms of publication volume, three academic journals have an impact factor of more than 10, six journals have an H-index of more than 100, and four journals have an H-index of more than 200. APPLIED CATALYSIS B-ENVIRONMENTAL has the highest impact factor (19.503), while ENVIRONMENTAL SCIENCE \& TECHNOLOGY has the highest H-index (345). From the above data analysis, it can be seen that articles in this field are usually published in some high-impact journals, which also reflects that the research in this field, at this stage, is relatively hot and innovative.

Table 3. Top 10 productive journals from 1997 to 2021.

\begin{tabular}{|c|c|c|c|c|c|c|c|}
\hline Rank & Journal & TP & TP R (\%) & TC & ССР & IF & H-Index \\
\hline 1 & PLASMA CHEMISTRY AND PLASMA PROCESSING & 77 & 6.5 & 1844 & 23.9 & 3.148 & 57 \\
\hline 2 & CHEMICAL ENGINEERING JOURNAL & 62 & 5.2 & 1938 & 31.3 & 13.273 & 172 \\
\hline 3 & JOURNAL OF HAZARDOUS MATERIALS & 44 & 3.7 & 1415 & 32.2 & 10.588 & 235 \\
\hline 4 & $\begin{array}{l}\text { APPLIED CATALYSIS B- } \\
\text { ENVIRONMENTAL }\end{array}$ & 42 & 3.6 & 294 & 70.1 & 19.503 & 205 \\
\hline 5 & JOURNAL OF PHYSICS D-APPLIED PHYSICS & 34 & 2.9 & 583 & 17.1 & 3.207 & 172 \\
\hline 6 & IEEE TRANSACTIONS ON PLASMA SCIENCE & 26 & 2.2 & 715 & 27.5 & 1.222 & 98 \\
\hline 7 & CHEMOSPHERE & 19 & 1.6 & 522 & 27.5 & 7.086 & 212 \\
\hline 8 & $\begin{array}{l}\text { PLASMA SCIENCE \& } \\
\text { TECHNOLOGY }\end{array}$ & 18 & 1.5 & 98 & 5.4 & 1.567 & 27 \\
\hline 9 & $\begin{array}{c}\text { ENVIRONMENTAL } \\
\text { SCIENCE \& TECHNOLOGY }\end{array}$ & 16 & 1.4 & 620 & 38.8 & 9.028 & 345 \\
\hline 10 & $\begin{array}{c}\text { JOURNAL OF } \\
\text { ELECTROSTATICS }\end{array}$ & 15 & 1.3 & 374 & 24.9 & 1.775 & 70 \\
\hline
\end{tabular}

Note: TP, number of total publications; TP R (\%), ratio of the number of one journal's publications to the total number of publications; TC, number of total citations; CPP, citations per publication; IF, impact factor in 2021; $\mathrm{H}$-index refers to his or her having, at most, $\mathrm{h}$ papers cited at least $\mathrm{h}$ times.

Table 4 shows the focus and proportion of subjects in this field in the past fifteen years. It is clear to see that the subject that has participated the most is engineering, with 441 articles published, accounting for $23.41 \%$. The second- and third-ranked disciplines are chemistry and physics, with 359 (19.06\%) and 281 (14.92\%) posts, respectively. The fourth place is environmental science and ecology, with 219 articles published, accounting for 11.62. The number of articles in the fields in fifth to tenth places is less than 100, and the proportion is relatively small. It can be seen that, in this field, the main focus is in the research of engineering, chemistry, physics, and environmental disciplines, while the disciplines of materials science mainly play a supporting role. 
Table 4. Top 10 productive territories from 1997 to 2021.

\begin{tabular}{cccc}
\hline Rank & Territory & TP & TP R (\%) \\
\hline 1 & Engineering & 441 & $23.41 \%$ \\
2 & Chemistry & 359 & $19.06 \%$ \\
3 & Physics & 281 & $14.92 \%$ \\
4 & Environmental Sciences and Ecology & 219 & $11.62 \%$ \\
5 & Materials Science & 81 & $4.30 \%$ \\
6 & Biochemistry and Molecular Biology & 64 & $3.40 \%$ \\
7 & Science and Technology-Other Topics & 64 & $3.40 \%$ \\
8 & Spectroscopy & 38 & $2.02 \%$ \\
9 & Instruments and Instrumentation & 28 & $1.49 \%$ \\
10 & Energy and Fuels & 27 & $1.43 \%$ \\
\hline
\end{tabular}

Note: TP is the number of total publications; TP R (\%) is the ratio of the number of one subject's publications to the total number of publications.

Figure 3 shows the trend chart of the number of articles issued by the top five disciplines in the past five years. It can be seen from the figure that all disciplines are on an upward trend as a whole, but individual disciplines have fluctuated in the volume of publications each year. For example, although the number of papers issued by engineering disciplines is the largest, the number of papers issued during 2017-2018 is less than that of chemistry disciplines, and the number of papers issued by engineering disciplines in 2020 is less than that in 2019. This may be because the arrival of the 2020 epidemic has affected the development of the engineering field, resulting in a decrease in the number of publications. Similarly, the number of articles in the field of engineering also decreased from 2016 to 2017. The possible reason is that the world economic crisis in 2016 affected the development of the field of engineering, so the number of articles in the field of engineering in 2017 and 2018 was relatively small. At the same time, the corresponding increase in the number of articles published in the field of environmental science and ecology can also support this conclusion; among the top five disciplines, only the two disciplines of physics and environmental science and ecology have maintained an upward trend in publishing articles, while the number of publications in this field in materials science has always been ranked last. It shows that this field is more a combination of basic science and practical application and has the characteristics of a multi-disciplinary intersection.

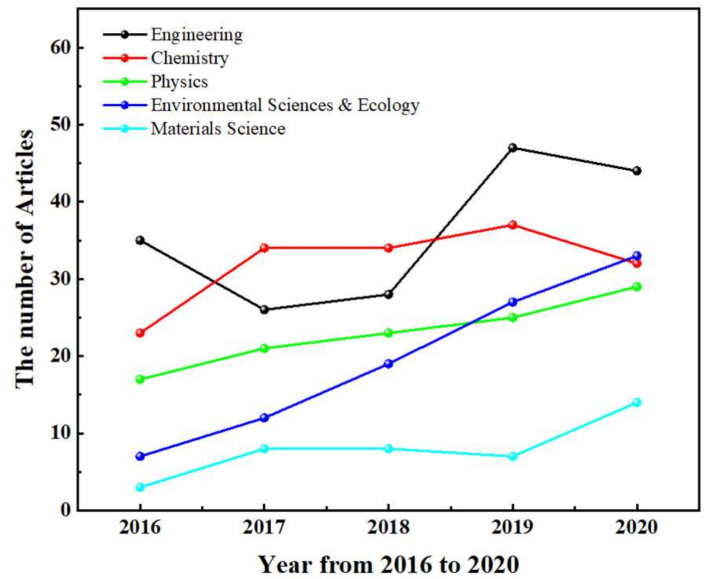

Figure 3. The annual number of each top 5 productive subjects during 2016-2020.

\subsection{Keyword Analysis}

For an article, author keywords often represent the theme and main idea of the article. At the same time, they also reflect the corresponding research fields and research directions. Author keywords can be analyzed from two aspects: on the one hand, they can be analyzed from the frequency of occurrence, which reflects the research enthusiasm of keywords in 
this field. On the other hand, they can be analyzed from the relationship between keywords; this reflects the relevance and intersection of the two keyword research fields. It can be said that keyword research reflects the research direction and research hotspots of a field. Based on the statistics of keywords, in the 1181 academic articles from 1997 to 2021, a total of 2645 keywords appeared with a total frequency of 4812. Among them, we merged the keywords of different expressions of "VOCs" ("vocs", "volatile organic compounds ", "volatile organic compound", "voc") into "volatile organic compounds", combined the keywords of different expressions of "NTP" ("non-thermal plasmas", "nonthermal plasma", "non thermal plasma", "non-equilibrium plasma", "low-temperature plasma") into "non-thermal plasma", and merged the keywords of different expressions of "DBD" ("dielectric barrier discharge plasma", "dielectric barrier discharge (dbd)", "dbd plasma") into "dielectric barrier discharge". Thus, the 20 keywords with the highest frequency in Table 5 were obtained. It can be seen from Table 5, excluding the two keywords used in our literature search, "volatile organic compounds" and "plasma", that keywords with a high frequency included "non-thermal plasma", "dielectric barrier discharge", "toluene", "ozone", "catalyst", " $\mathrm{TiO}_{2}$ ", etc. The above information shows that the dielectric barrier discharge low-temperature plasma catalytic degradation of VOCs has the most research interest in this field.

Table 5. The 20 most frequent keywords from 1997 to 2021.

\begin{tabular}{cccccc}
\hline Author Keyword & $\mathbf{9 7 - 2 1 ~ T P}$ & $\mathbf{9 7 - 2 1 ~ R ~ ( \% ) ~}$ & Author Keyword & $\mathbf{9 7 - 2 1 ~ T P}$ & $\mathbf{9 7 - 2 1 ~ R ~ ( \% ) ~}$ \\
\hline volatile organic compounds & 251 & $1(26.5)$ & TiO2 & 24 & $11(2.5)$ \\
non-thermal plasma & 208 & $2(22)$ & photo catalysis & 23 & $12(2.4)$ \\
dielectric barrier discharge & 127 & $3(13.5)$ & oxidation & 22 & $13(2.3)$ \\
toluene & 89 & $4(9.4)$ & adsorption & 22 & $13(2.3)$ \\
plasma & 75 & $5(7.9)$ & corona discharge & 19 & $15(2)$ \\
ozone & 49 & $6(5.2)$ & catalytic oxidation & 19 & $15(2)$ \\
catalyst & 42 & $7(4.4)$ & voc removal & 18 & $17(1.9)$ \\
plasma catalysis & 36 & $9(3.8)$ & decomposition & 17 & $18(1.8)$ \\
catalysis & 35 & $10(3)$ & trichloroethylene & 16 & $19(1.7)$ \\
benzene & 28 & synergetic effect & 13 & $20(1.4)$ \\
\hline
\end{tabular}

Note: TP: Total numbers of publications. R (\%): Rank (the percentage of articles in total publications is given within brackets).

According to the relevance of the author's keywords in the same article and different articles, VOSviewer was used to merge and organize the author's keywords. In order to facilitate the display, "volatile organic compounds", "non-thermal plasma", and "dielectric barrier discharge" were replaced with "VOCS", "ntp", and "dbd", respectively, to reduce the mutual occlusion in the picture caused by the long vocabulary. From this, the author keyword cluster map from 1997 to 2021 shown in Figure 4 was obtained. It can be seen that the keywords that are most closely related to the two search keywords include DBD, NTP, plasma-catalysis, ozone, $\mathrm{TiO}_{2}$, etc. Among them, the representative plasma type is NTP; DBD is the most closely related to the discharge form. The keywords that represent the type of catalyst and appear the most are related to titanium-containing catalysts, such as $\mathrm{TiO}_{2}$; this can also prove, from another aspect, that the dielectric barrier discharge non-thermal plasma catalytic degradation of VOCs has the highest research interest in this field. 


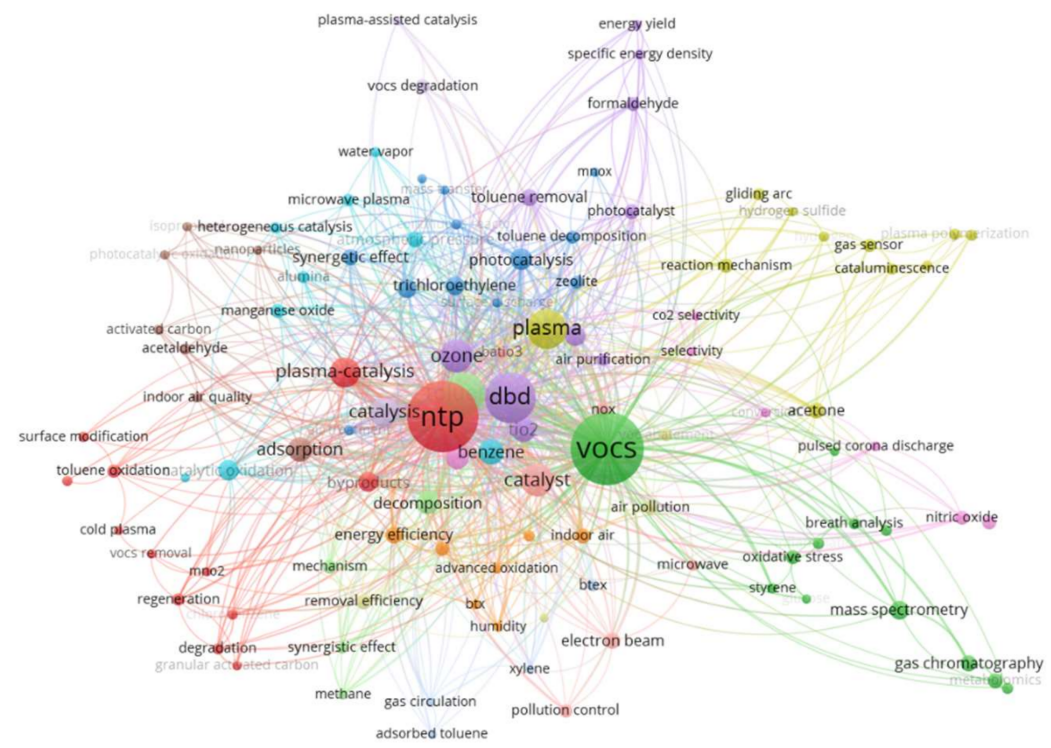

Figure 4. Author keyword cluster map from 1997 to 2021.

\section{Hot Issues and Review}

This chapter is intended to summarize the key content and hotspots obtained from the above data analysis. According to the above analysis of the author's keywords and the intimacy between the author's keywords, it can be seen that, in this field, low-temperature plasma and plasma catalysis are the main research hotspots. Therefore, this chapter selects the "dielectric barrier discharge", which can be a representative form of plasma discharge, and the most frequently occurring catalyst type, the titanium-containing catalyst, as two hotspots for review.

\subsection{Dielectric Barrier Discharge Plasma}

\subsubsection{What Is the DBD and Micro-Discharge?}

Dielectric barrier discharge is a form of discharge based on dielectric barrier discharge plasma. It is a gas discharge with an insulating medium intervening in the discharge space. It can generate non-thermal plasma under normal pressure conditions, so it can also be called dielectric barrier discharge non-thermal plasma. It also possesses a wide range of applications in environmental protection, materials, physics, chemistry, and other fields. The common dielectric barrier discharge low-temperature plasma structure can be divided into two types: plate type and coaxial cylinder type. It can put one or more layers of the insulating medium into the discharge area to achieve some special purposes. As shown in Figure 5 (where blue represents the barrier medium, gray represents the electrode material): (a) plate DBD reactor; (b) coaxial cylindrical DBD reactor $[39,40]$.

The process of dielectric barrier discharge is usually divided into three stages, namely, discharge breakdown, charge transfer, and particle excitation. As the most important part of dielectric barrier discharge, micro-discharge appears in the process of discharge breakdown and charge transfer. In the initial stage of micro-discharge, with the increase of the applied electric field energy, more and more electrons accumulate on the surface of the medium, and the accumulation of electrons, to a certain extent, causes an avalanche of electrons, forming a micro-discharge channel. At the end stage of the micro-discharge, with the impact of some excited electrons on gas molecules and the micro-discharge effect, a large number of excited particles that are difficult to obtain under normal conditions are generated in the discharge area. These excited particles form the energy basis for the surface modification of materials. 


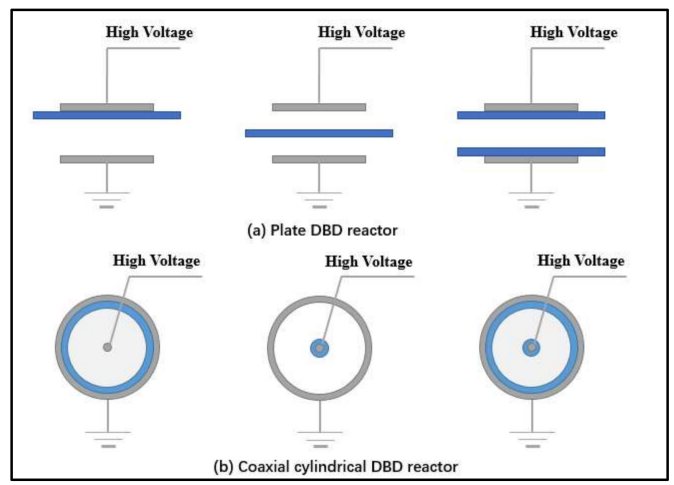

Figure 5. Plate and coaxial cylindrical DBD reactors. (a) plate DBD reactor; (b) coaxial cylindrical DBD reactor.

\subsubsection{Effect of Reactor}

Many factors affect the form and intensity of the dielectric barrier discharge plasma discharge, including electrode material, discharge gap and length, medium material, etc. Among them, the difference in the structure of the reactor can directly affect the DBD plasma discharge form, thereby affecting the discharge intensity and discharge efficiency of the DBD plasma.

A suitable electrode material not only meets the discharge requirements of DBD non-thermal plasma to the greatest extent, but also meets the lowest energy consumption. DBD plasma has a wide variety of electrode materials, such as stainless steel [41], copper [42], nickel [43], metal oxides [44], etc. The electrode structure is mostly plate, rod, coil, and other structures. For example, Jahanmiri et al. [45] used rod electrodes made of aluminum, copper, stainless steel, iron, and brass as high-voltage electrodes and aluminum foil as ground electrodes for performance research. Results show that the electrode materials are significantly different in energy consumption, where $\mathrm{Fe}>$ brass $\sim \mathrm{Cu}>\mathrm{Al} \sim$ steel. In addition, if stainless steel is used instead of copper as a high-voltage electrode, energy efficiency can be improved by $123 \%$. Li et al. [46] studied the degradation of toluene in the DBD plasma system with different electrode structures, the results show that, under the same dual-dielectric material conditions, the rod-shaped, high-voltage electrode is better than the coil electrode in the degradation efficiency of toluene. The possible reason is that the degradation process of toluene is mainly carried out in the inner tube. The rod electrode can strengthen the electric field intensity of the inner tube, while the coil electrode shows better performance with the increase of the electric field intensity of the outer tube. However, in the study of Jiang et al. [47], the degradation efficiency of benzene with coil electrodes, rod electrodes, and bolt electrodes in a dielectric barrier/packed-bed discharge plasma reactor was compared. The degradation efficiency of the coil electrode to benzene was significantly better than that of the high-voltage electrodes of the other two structures. The reason is that the coil electrode reduces the dielectric loss of the insulating dielectric layer during the reaction, which is beneficial to the enhancement of the DBD reaction on the dielectric surface. Therefore, different electrode materials and different electrode structures have their own advantages in different reaction systems, and it is impossible to use a single standard to measure which electrode material and structure is the best choice.

Different discharge gaps usually have two sides. On the one hand, increasing the discharge gap can increase the residence time of the target gas in the reaction zone, thereby enhancing the effect. On the other hand, the increase of the discharge gap reduces the intensity of the electric field in a disguised form, resulting in a decrease in the treatment effect of the target gas. Li et al. [19] summarized the research and presented that the discharge gap of DBD plasma is generally between 1 and $15 \mathrm{~mm}$. Mustafa et al. [48] compared the conversion efficiency of methane under the same DBD plasma catalytic system with a discharge gap of $3 \mathrm{~mm}$ and $6 \mathrm{~mm}$, respectively. The results show that, when the power and discharge gap are controlled at $65.8 \mathrm{~W}$ and $6 \mathrm{~mm}$, the average conversion 
rate of methane can reach $56 \%$. In addition, when the discharge gap is $3 \mathrm{~mm}$ under the same condition, the average conversion rate of methane can reach 76\%. Namita Ojah et al. [49] studied the effect of the discharge gap on the surface treatment of the material under the conditions of $6 \mathrm{~mm}$ and $10 \mathrm{~mm}$; under the condition of $6 \mathrm{~mm}$, the results of surface treatment of nanomaterials are better than the surface mechanical strength and surface wettability of materials with a discharge gap of $10 \mathrm{~mm}$ and untreated materials. In addition, the surface cell adhesion and value-added ability of the material processed under the condition of $6 \mathrm{~mm}$ discharge gap is significantly higher than that of the unprocessed material. Jin et al. [50] used a trapezoidal structure reactor as a basis and, at the same time, studied the discharge in DBD plasma with a distance of $1-7 \mathrm{~mm}$. When the pulse frequency was $500 \mathrm{~Hz}$ and the discharge gap was less than $5 \mathrm{~mm}$, the discharge area presented a uniform layer discharge, and the discharges were all diffuse; when the pulse frequency was $1 \mathrm{kHz}$, the discharge in the discharge space presented irregular filamentary discharge, and the uniform discharge layer disappeared synchronously. Jiang et al. [51] increased the electrode spacing of the reactor from $20 \mathrm{~mm}$ to $40 \mathrm{~mm}$, which reduced the degradation efficiency of toluene; increasing the electrode gap can increase the residence time of the pollutant gas, but it reduces the average electric field strength and specific input energy (SIE, which is a good indication of the energy delivered to the reactor) in a disguised form. In other words, in the DBD plasma system, the residence time of pollutant gases in the system plays a secondary role in the degradation of pollutants, while the average electric field strength and SIE play a leading role. Therefore, in order to achieve the maximum working efficiency of DBD plasma, it is necessary to weigh the pros and cons between the electric field strength and the residence time and to find the best experimental parameters through continuous experimental optimization.

Generally speaking, discharge length also has a certain influence on discharge efficiency. On the one hand, the length of the discharge affects the residence time of the pollutant gas in the system, as well as the number of micro-discharges, and the increase of the residence time and micro-discharges can increase the contact and collision of active species and electrons with target pollutants [52]. On the other hand, under the same input power condition, the increase of the discharge length reduces the power density [53]. Lee et al. [54] studied the effect of segmented electrode structure on toluene degradation under the DBD plasma catalytic system. Figure 6 shows that, at the same total discharge length, the discharge length was divided into one segment, two segments, and four segments. After the introduction of the segmented discharge structure, the current law of DBD plasma is reflected as follows: $\mathrm{I}_{\text {four-stage }}>\mathrm{I}_{\text {two-stage }}>\mathrm{I}_{\text {one-stage; }}$ when the electric field intensity remains unchanged, due to the increase in current, the SIE increases simultaneously, which, ultimately, leads to an increase in the degradation rate of toluene, the mineralization rate, and $\mathrm{CO}_{2}$. Jiang et al. [51] demonstrated the degradation of toluene with different discharge lengths in a continuous-flow sliding dielectric barrier discharge (SLDBD) reactor. Under the given $U_{+ \text {pulse }}$ condition, as the discharge length continued to increase, the electric field intensity in the system also continued to increase. The reason is that the increase of the discharge length leads to the longer residence time of the pollutants in the system and the increase of the continuous discharge energy, thereby increasing the degradation performance and energy performance of the SLDBD plasma system. Guo et al. [55] compared the degradation of ethyl acetate by the double dielectric barrier discharge (DDBD) reaction system when the discharge length was $12.5 \mathrm{~mm}, 25 \mathrm{~mm}$, and $50 \mathrm{~mm}$. When the discharge length increased from $12.5 \mathrm{~mm}$ to $50 \mathrm{~mm}$, the degradation rate of ethyl acetate continued to increase, reaching a maximum of $80.8 \%$. At the same time, with the increase of the discharge length, the residence time of ethyl acetate in the DDBD reactor also increased from $0.12 \mathrm{~s}$ to $0.48 \mathrm{~s}$, which also explains the increase in the degradation rate of ethyl acetate under the condition of increasing discharge length. However, Wang et al. [53] studied the conversion of methane by the dielectric barrier discharge micro-plasma and found that, at a constant input power, the increase of the discharge length reduces the power density of the reaction zone, resulting in a decrease in the conversion rate of the target 
gas. In addition, the heat dissipation of the dielectric layer in the reaction also increases with the increase of the discharge length, resulting in more energy loss. Therefore, in the research, the discharge length suitable for the experimental requirements can be considered according to the focus of different experiments, so as to maximize the utilization effect of the DBD plasma reaction system.

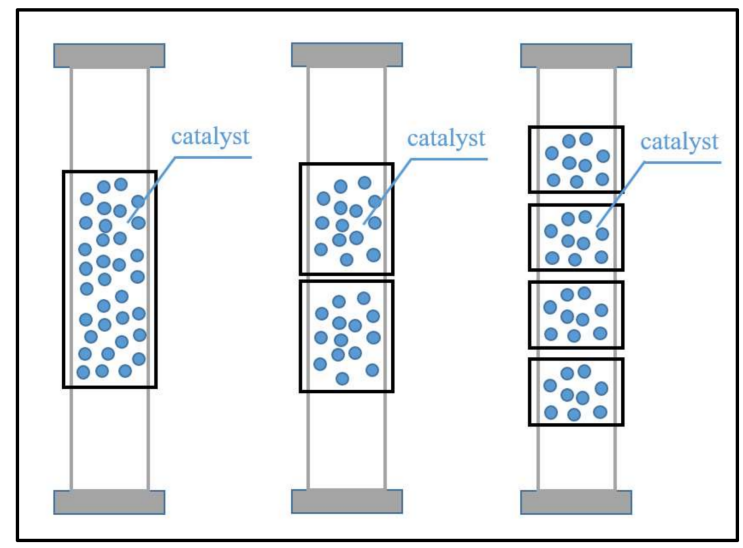

Figure 6. One-stage, two-stage, four-stage electrode discharge structure diagram.

Dielectric material affects the discharge intensity and micro-discharge due to the difference in dielectric constant. The difference in the dielectric constant of different dielectric materials leads to the difference in dielectric capacitance; the dielectric capacitance and the air gap capacitance are connected in series in the circuit. Increasing the dielectric capacitance increases the electric field strength of the discharge gap, resulting in more micro-discharges [19]. Common dielectric materials include glass [56-58], quartz [59], plexiglas [33], alumina [60], ceramics [61], and polytef [51]. Quartz dielectric materials have been widely used in research and commercialization due to the characteristics of heat resistance, high strength, and high cost performance [62]. In the research, it was found that, in addition to quartz dielectric, other dielectric materials were also studied by scholars because of some special properties. Wang et al. [63] found that, in the DBD plasma system, the dielectric material changes the electric field strength in the discharge gap by changing the equivalent dielectric capacitance. Li et al. [64] studied the auxiliary discharge behavior of two dielectric materials of zirconia $(\varepsilon=25)$ and polytetrafluoroethylene $(\varepsilon=25)$ in a DBD packed-bed reactor. The effects of two dielectric materials on the production of active particles in the DBD plasma catalytic system and their kinetics were described. Four types of discharge process, including high-voltage side streamer discharge and ground side dielectric surface discharge, were produced. Moreover, the discharge generation mechanism of two nitrogen-active species and one oxygen-active species was revealed, and research confirmed that PTFE dielectric materials have better active species excitation performance than zirconia dielectric materials. Kundu et al. [65] studied the difference in the discharge properties of quartz and alumina dielectric materials in the DBD plasma system. The results show that, although the electric field strength in the reactor with alumina medium is lower than that in the reactor with quartz medium, the dielectric constant of alumina medium is greater than that of quartz medium. The dielectric capacity and micro-discharge density in the discharge gap are higher than that of the quartz medium, so the installation of the alumina medium reactor can obtain a higher methane conversion rate. Similarly, Khoja et al. [66] explored the $\mathrm{CO}_{2}$ conversion rate of methane by comparing quartz dielectric materials and alumina dielectric materials. The results show that, under the same conditions, the maximum conversion rates of methane and $\mathrm{CO}_{2}$ of alumina are $74 \%$ and $68 \%$, respectively, while the $\mathrm{CO} / \mathrm{H}_{2}$ ratio and energy efficiency are higher than those of quartz dielectric materials. This is because the porous and fluffy nature of alumina increases the residence time of the gas in the discharge area, resulting in more particles colliding with the target gas molecules, thereby increasing the large conversion efficiency. 
That porous materials increase the adsorption of target gas molecules and residence time in the discharge area has also been confirmed in previous studies $[57,67]$.

\subsubsection{Summary}

Among the factors that affect the degradation of VOCs in the DBD plasma system, the structural factor of DBD has a decisive impact. The main reason is that factors, such as electrode material, discharge gap and length, and medium material, change the equivalent capacitance of the discharge area to varying degrees and so achieve the effect of changing the discharge form and discharge intensity in order to improve the degradation efficiency and mineralization rate of VOCs by the DBD plasma system, etc. In fact, there are relatively few studies on DBD reactors, mainly due to the relative lack of research on the discharge behavior and the complexity of gas discharges by researchers [9]. In addition, compared with an effective, packed catalyst, simply changing the reactor structure has a limited effect on the overall system performance. The filling of the catalyst not only changes the degradation efficiency of VOCs, but also has many advantages in the degradation of harmful by-products, degradation of $\mathrm{O}_{3}$, improvement of mineralization rate, and carbon balance. Titanium-containing catalysts not only have greater advantages in the catalytic degradation of VOCs but are also widely favored by researchers due to their special photoelectric properties. Therefore, the research on coupling titanium-containing catalysts in the research of DBD plasma system is also a development trend.

\subsection{DBD Plasma Synergizes with Titanium-Containing Catalysts to Degrade VOCs}

In order to study the degradation of VOCs by DBD low-temperature plasma with titanium-containing catalysts, it is necessary to identify target pollutants and classify the specific role of different titanium-containing catalysts in DBD plasma to determine the corresponding catalyst types and forms required for the degradation of different pollutants.

\subsubsection{Target Pollutants}

In the process of discharging various industrial pollutants, there are hundreds of different types of VOC, and the efficient and harmless degradation of VOCs is still a major difficulty in environmental governance. Table 6 summarizes the basic situation of different target pollutants in various studies of DBD and titanium-containing catalysts in the past ten years. According to the different chemical structures of these target pollutants, we divided them into several categories: aromatics, ketones, aldehydes, alcohols, alkanes, alkenes, and halocarbons. In the DBD and titanium-containing catalyst catalytic system, the research on aromatics (such as toluene, benzene, styrene, etc.) is the most frequent among the research on conventional VOCs. Chen et al. [68] studied the degradation efficiency and mineralization rate of toluene in the catalytic system of DBD and $\mathrm{a} \mathrm{TiO} 2 / \mathrm{Al}_{2} \mathrm{O}_{3}-\mathrm{Co}_{3} \mathrm{O}_{4} / \mathrm{AC}$ (Ti-Co) catalyst. When the relative humidity was $30 \%$, the specific input energy was $65 \mathrm{~J} \cdot \mathrm{L}^{-1}$, and the pollutants in the DBD discharge area passed through a $10 \mathrm{~cm} \mathrm{TiO} 2 / \mathrm{Al}_{2} \mathrm{O}_{3}$ catalystpacked column and a $20 \mathrm{~cm} \mathrm{Co}_{3} \mathrm{O}_{4} / \mathrm{AC}$ (Ti-Co) catalyst-packed column, respectively; the degradation efficiency of toluene and the selectivity of carbon dioxide reached $72 \%$ and $44 \%$, respectively. Liu et al. [69] researched the degradation of toluene and the selectivity of carbon dioxide under the synergistic catalytic system of $\mathrm{DBD}$ and $\mathrm{TiO}_{2}-\mathrm{C} / 5 \mathrm{~A}$. The results show that, when the DBD discharge area is filled with $\mathrm{TiO}_{2}-\mathrm{C} / 5 \mathrm{~A}$ catalyst, the toluene degradation efficiency and carbon dioxide selectivity reach $99.6 \%$ and $83 \%$, respectively, which is much higher than the $79.5 \%$ and $37.5 \%$ achieved when filled with no catalyst. This is because the doping of carbon facilitates the generation of photoelectron holes, reduces the energy band gap, and facilitates the growth of more active species on the surface of the catalyst. In addition to the research on aromatics, scholars have also studied the degradation of other types of VOC in the catalytic systems of DBD and titaniumcontaining catalysts. Zeng et al. [70] used DBD plasma to explore the influencing factors and mechanism of $\mathrm{Cu}$-doped $\mathrm{MnO}_{2}$ catalysts to degrade acetone and methyl ethyl ketone. In the degradation process of acetone and methyl ethyl ketone, the degradation efficiency 
of methyl ethyl ketone was always higher than that of acetone, and the maximum value could reach $97 \%$. The reason is that the doping of $\mathrm{Cu}$ accelerates the generation of surface active substances, thereby accelerating the efficiency of the reaction. At the same time, the doping of $\mathrm{Cu}$ can also optimize the utilization of ozone and the complete oxidation of VOCs. Ghaida et al. [71] found that the simultaneous application of NTP and UV is favorable for the cleavage of butyl groups on VOCs, and the addition of $\mathrm{TiO}_{2}$ promotes the degradation of butyraldehyde, reduces the release of ozone, and improves the mineralization rate and $\mathrm{CO}_{2}$ selectivity. Sivachandiran et al. [72] investigated the relative humidity of the air on the adsorption and regeneration of isopropanol on the $\mathrm{TiO}_{2}$ catalyst. The humidity slowed the adsorption of isopropanol on the catalyst surface but played a positive role in increasing the mineralization rate and reducing by-products. Zhang et al. [73] compared traditional $\mathrm{TiO}_{2}$ and $\mathrm{TiO}_{2}$-coated $\gamma-\mathrm{Al}_{2} \mathrm{O}_{3}$ catalysts prepared by sol-gel method in synergistically removing styrene from DBD. Among them, nano- $\mathrm{TiO}_{2}$-coated catalysts had more catalytic oxidation activity than traditional catalysts. Simultaneously, compared with traditional catalysts, the catalyst prepared by the sol-gel method had an increase in the degradation rate of ozone of $18 \%$, and the phenomenon of carbon deposition was also significantly reduced.

Table 6. Overview of various VOCs degraded by DBD and titanium-containing catalysts.

\begin{tabular}{|c|c|c|}
\hline Classification & VOCs & Reference \\
\hline \multirow[t]{6}{*}{ Aromatics } & Toluene & {$[68,69,74-81]$} \\
\hline & Styrene & [82-84] \\
\hline & Benzene & {$[85,86]$} \\
\hline & Xylene & [87] \\
\hline & Phenol & [35] \\
\hline & Naphthalene & {$[83,88]$} \\
\hline \multirow[t]{3}{*}{ Ketones } & Acetone & {$[70,89]$} \\
\hline & Methyl ethyl ketone & [70] \\
\hline & Butane-2,3-dione and Heptan-2-one & [90] \\
\hline \multirow[t]{3}{*}{ Aldehydes } & Formaldehyde & [91] \\
\hline & Acetaldehyde & [92] \\
\hline & Butyraldehyde & [71] \\
\hline Alcohols & Isopropanol & {$[72,89]$} \\
\hline Alkanes & Butane & {$[93,94]$} \\
\hline Alkenes & Ethylene & {$[73,94]$} \\
\hline \multirow[t]{2}{*}{ Halocarbons } & Chlorobenzene & [95] \\
\hline & Chloroform & [96] \\
\hline
\end{tabular}

In addition, most of the research on VOCs was carried out around the $\mathrm{C}-\mathrm{H}-\mathrm{O}$ composition type of VOC, and we cannot ignore that there is a class of VOC containing halogen elements, such as chlorobenzene, chloroform, etc. The toxicity for this type of VOC is usually relatively large, and the impact on the environment and humans is also more serious. Song et al. [95] studied the degradation of chlorobenzene in a DBD catalytic system using $\mathrm{CoMn} / \mathrm{TiO}_{2}$ and $\mathrm{CeMn} / \mathrm{TiO}_{2}$ catalysts. The results show that, when NTP was present, the catalytic activity of the $\mathrm{CoMn} / \mathrm{TiO}_{2}$ catalyst was significantly better than that of $\mathrm{CeMn} / \mathrm{TiO}_{2}$; the degradation efficiency of chlorobenzene reached $97.1 \%$ and a carbon dioxide selectivity of $65.5 \%$ on a calculated carbon balance of $99.1 \%$, respectively. However, under thermo-catalytic conditions, the effects of the two catalysts were completely opposite. According to the relevant by-products and characterization analysis, it was finally concluded that NTP plays a leading role in the degradation of chlorobenzene, and the catalyst plays a major role in reducing the formation of harmful by-products.

\subsubsection{Titanium-Containing Catalysts}

Normally, the titanium-containing catalysts filled in DBD low-temperature plasma include ferroelectrics-type catalysts [81,97-99] (e.g., $\mathrm{BaTiO}_{3}$, etc.), semiconductor $[78,83,86,95,100-107]$ $\left(\mathrm{TiO}_{2}\right)$-supported catalysts, and titanium-supported catalysts [108-113] (e.g., $\mathrm{TiO}_{2} / 5 \mathrm{~A}$, $\mathrm{TiO}_{2} / \gamma-\mathrm{Al}_{2} \mathrm{O}_{3}$, etc.). The most common type is the titanium-supported catalyst, which 
mainly improves the electric field strength and micro-discharge through the good dielectric properties of titanium dioxide, which increase the degradation efficiency of pollutants. The support of titanium can also enhance the formation of surface active groups on the catalyst, thereby increasing the mineralization rate and suppressing the formation of harmful by-products. Gandhi et al. [93] used a $\mathrm{TiO}_{2}$-loaded glass wool (GW) catalyst to explore the degradation performance of butane in a DBD catalytic system. Although there is no difference in the degradation of butane between GW loaded with $\mathrm{TiO}_{2}$ and pure GW, GW loaded with $\mathrm{TiO}_{2}$ shows good catalytic performance in terms of mineralization rate and $\mathrm{CO}_{2}$ selectivity. Tang et al. [35] compared the phenol degradation rate of granular activated carbon (GAC) and $\mathrm{TiO}_{2}-\mathrm{GAC}$ hybrid materials in the DBD plasma catalytic system. The $\mathrm{TiO}_{2}-\mathrm{GAC}$ hybrid material had better phenol degradation efficiency than the GAC material in a DBD plasma system; the highest degradation efficiency reached $88 \%$, and it also had better performance in catalyst activation and regeneration. This is actually due to the increased active species, such as hydroxyl groups, on the GAC surface, caused by the addition of titanium. Zhu et al. [114] studied the degradation of toluene by a titanium-doped composite catalyst, and the results showed that the toluene degradation efficiency of the titanium-doped, double-nucleated catalyst can reach $99 \%$ under an energy efficiency of $2.1 \mathrm{~g} / \mathrm{kWh}$. Gandhi et al. [94] compared the $\mathrm{TiO}_{2}-$ and $\mathrm{ZrO}_{2}$-coated $\gamma-\mathrm{Al}_{2} \mathrm{O}_{3}$ filling materials under the DBD NTP system at $150{ }^{\circ} \mathrm{C}$ and studied the degradation of butane and ethylene. The degradation efficiency of $\mathrm{TiO}_{2}$-coated $\gamma-\mathrm{Al}_{2} \mathrm{O}_{3}$ was higher than that of $\gamma-\mathrm{Al}_{2} \mathrm{O}_{3}$ alone, but it produced a large amount of formaldehyde, acetaldehyde, and other harmful by-products. The $\mathrm{ZrO}_{2}$-coated $\gamma-\mathrm{Al}_{2} \mathrm{O}_{3}$ showed good performance in reducing harmful by-products and increasing the mineralization rate. Zhu et al. [115] studied the effect of an $\mathrm{F}-\mathrm{TiO}_{2} / \gamma-\mathrm{Al}_{2} \mathrm{O}_{3}$ composite catalyst on the degradation of toluene. The experimental results show that the filling of $\mathrm{F}-\mathrm{TiO}_{2} / \gamma-\mathrm{Al}_{2} \mathrm{O}_{3}$ catalyst can reach a high degradation rate of toluene ( $>99 \%$ ). The reason is that the doping of $\mathrm{F}_{-} \mathrm{TiO}_{2}$ increases the porosity and pore structure of the catalyst, so that the catalyst has a better adsorption performance for toluene, thereby increasing the degradation efficiency of toluene. The research on semiconductor $\left(\mathrm{TiO}_{2}\right)$-supported catalysts is mainly the combination of electro-catalysis and photocatalysis. $\mathrm{TiO}_{2}$ has better photocatalytic performance; photocatalysis is actually the photocatalytic oxidation process (PCO), which occurs when electrons on the surface of the catalyst receive energy greater than that required for electron transitions and provide strong oxidative properties through the generated electron holes (Figure 7) [116]. The key reactions related to photocatalytic oxidation are as follows (Table 7): firstly, the $\mathrm{TiO}_{2}$ catalyst generates electron holes and free electrons by absorbing light energy, and then the free electrons generate $\mathrm{O}_{2}{ }^{-}$and $\mathrm{H}_{2} \mathrm{O}$ by hitting $\mathrm{O}_{2}$ and $\mathrm{H}_{2} \mathrm{O}$. Finally, under the action of $\mathrm{PCO}, \mathrm{VOC}$ react with $\mathrm{O}_{2}{ }^{-}$and $\mathrm{OH}^{-}$to form the final products $\mathrm{CO}_{2}$ and $\mathrm{H}_{2} \mathrm{O}[116,117]$. For $\mathrm{TiO}_{2}$, it can utilize the energy generated by many kinds of light sources (including the light energy generated by plasma discharge) because $\mathrm{TiO}_{2}$ has a wide band gap. In addition, its higher dielectric constant can improve the electrocatalytic performance of $\mathrm{TiO}_{2}$ in a packed bed. During the discharge of DBD plasma, in addition to the inherent electrical properties of micro-discharge, it also exhibits some of the light properties caused by the discharge. Therefore, the combination of a $\mathrm{TiO}_{2}$-supported catalyst and DBD can amplify the advantages of both and achieve the greatest photoelectric catalytic effect. Barakat et al. [89] studied the oxidation performance of isopropanol (IPA) and acetone on the surface of a $\mathrm{TiO}_{2}$-packed bed in a DBD plasma reactor. In the study, it was found that there was a strong competitive adsorption between IPA and acetone, and the adsorption capacity of IPA was significantly higher than that of acetone. During this period, part of the IPA was oxidized to acetone, which caused a significant decrease in the adsorption amount of acetone and continued release due to occupying part of the acetone adsorption sites. At the same time, in an acetone atmosphere, NTP produced a close amount of $\mathrm{CO}_{2}$ under unit energy input, indicating that the production of $\mathrm{CO}_{2}$ depends on the $\mathrm{S} 2$ adsorption sites [118,119] that can adsorb acetone. Therefore, increasing the number of S2 adsorption sites is also a solution for improving $\mathrm{CO}_{2}$ selectivity. Karuppiah et al. [86] studied the 
performance of a $\mathrm{TiO}_{2} / \mathrm{MnO}_{\mathrm{x}}$-modified catalyst in the degradation of dilute benzene under DBD plasma photoelectric catalysis. During the degradation process of dilute benzene, the in-situ growth of ozone on the surface of $\mathrm{MnO}_{\mathrm{x}}$ led to the generation of atomic oxygen, and the main function of $\mathrm{TiO}_{2}$ was to generate ultraviolet light-induced catalytic oxidation. The organic combination of the two materials achieved the best photoelectric catalytic effect. Guaitella et al. [107] studied the photoelectrocatalytic degradation of $\mathrm{C}_{2} \mathrm{H}_{2}$ by the hybrid material of $\mathrm{TiO}_{2}$ and glass fiber under DBD and UV. The results showed that the removal of $\mathrm{C}_{2} \mathrm{H}_{2}$ by the porous structure of the hybrid material depends on the generation of oxygen atoms on the surface of the material. Under the condition of external UV, the photocatalytic performance of the $\mathrm{TiO}_{2}$ material surface to the plasma inherent discharge excitation was weak, but it relied heavily on the activation of the photocatalytic performance of the external UV. The combination of a ferroelectrics-type catalyst and DBD is mainly manifested by the high dielectric constant of the material. A higher dielectric constant can usually generate greater electric field strength and more micro-discharges in the plasma discharge section to improve the synergistic catalytic effect. Jiang et al. [98] explored the effect of $\mathrm{BaTiO}_{3}$ catalyst packed-bed DBD reactor on the degradation of benzene. The experimental results show that, in the quartz medium reactor, under the conditions of $\mathrm{BaTiO}_{3}$ catalyst filling, it showed better benzene degradation performance, but the performance in energy yield was poor. Zhu et al. [99] compared toluene degradation under four DBD packed-bed process conditions: no filler, ceramic ring, $\mathrm{BaTiO}_{3}$ ring, and $\mathrm{Ba}_{0.8} \mathrm{Sr}_{0.2} \mathrm{Zr}_{0.1} \mathrm{Ti}_{0.9} \mathrm{O}_{3}$ ring. Through comparison, it was found that the degradation efficiency of toluene in the catalytic system filled with $\mathrm{Ba}_{0.8} \mathrm{Sr}_{0.2} \mathrm{Zr}_{0.1} \mathrm{Ti}_{0.9} \mathrm{O}_{3}$ ring could reach $97 \%$, and the energy efficiency brought by this catalyst was also higher than that under other filling conditions. This is because the collision of high-energy electrons with gas under the modified catalytic system produces more active free radical groups. These active particles can further react with toluene and, simultaneously, improve the degradation efficiency and mineralization rate of toluene. Jeong et al. [97] explored the degradation efficiency of toluene by ferroelectric catalysts supported by different metal oxides at a voltage of $5 \mathrm{kV}$. The order of catalyst activity was $\mathrm{MnO}_{2} / \mathrm{BaTiO}_{3}>\mathrm{Co}_{3} \mathrm{O}_{4} / \mathrm{BaTiO}_{3}>\mathrm{CuO} / \mathrm{BaTiO}_{3}>\mathrm{BaTiO}_{3}$; among them, $\mathrm{MnO}_{2} / \mathrm{BaTiO}_{3}$ showed a good activity life during the $230 \mathrm{~h}$ catalyst activity test, and the degradation efficiency did not decrease. Simultaneously, the $\mathrm{MnO}_{2} / \mathrm{BaTiO}_{3}$ catalyst also showed good performance in ozone degradation.

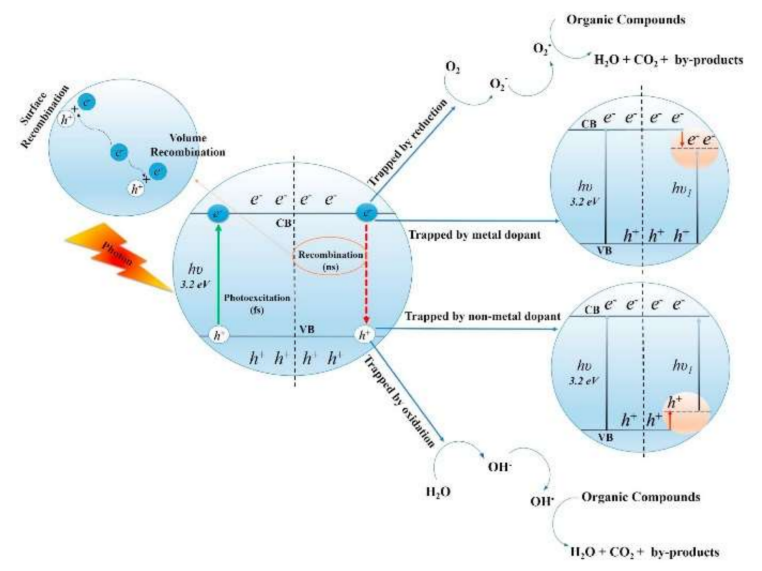

Figure 7. Basic principle of PCO for removal of VOCs, reproduced with permission from [116], 2018, Elsevier. 
Table 7. $\mathrm{TiO}_{2}$ photocatalytic oxidation process for the degradation of VOC pollutants.

\begin{tabular}{cc}
\hline Reactions & Equation Number \\
\hline $\mathrm{TiO}_{2}+\mathrm{h}_{1} \rightarrow \mathrm{e}_{\mathrm{h}}^{+}+\mathrm{e}^{-}$ & 1 \\
$\mathrm{O}_{2}+\mathrm{e}^{-} \rightarrow \mathrm{O}_{2}^{-}$ & 2 \\
$\mathrm{H}_{2} \mathrm{O}+\mathrm{e}^{-} \rightarrow \mathrm{OH}^{-}$ & 3 \\
VOCs $+\mathrm{O}_{2}^{-}+\mathrm{OH}^{-} \rightarrow \mathrm{H}_{2} \mathrm{O}+\mathrm{CO}_{2}+$ by-products & 4 \\
\hline
\end{tabular}

Note: where $\mathrm{e}_{\mathrm{h}}{ }^{+}$and $\mathrm{e}^{-}$are electron hole and electron, respectively; $\mathrm{h}_{\mathrm{l}}$ is light energy.

\subsubsection{Summary}

In the research of DBD plasma synergistic titanium-containing catalysts, the target pollutants were mainly aromatics, ketones, aldehydes, alcohols, alkanes, alkenes, and halocarbons, etc. The most studied was the degradation of aromatics, which may be attributed to the ubiquitous characteristic of aromatics in our lives. In addition, the organic compound has the greatest impact on human health. However, there are relatively few studies on halocarbons in this field. Halocarbons are oxidized in the atmosphere to various chlorinated by-products, which will harm human health while also having a huge impact on the ecological environment. Therefore, researchers also need to pay more attention to the degradation of halocarbons. From the perspective of titanium-containing catalysts, the three types of catalyst play different roles in the DBD plasma catalytic system. Titanium-supported catalysts mainly rely on the good dielectric properties of the surface, titanium-containing materials to improve the degradation efficiency of pollutants. Additionally, the support of titanium enhances the formation of catalyst surface active groups, thereby increasing the mineralization rate and inhibiting the formation of harmful by-products. The degradation of VOCs by a $\mathrm{TiO}_{2}$-supported catalyst depends on its good photoelectric catalytic properties; ferroelectrics-type catalysts also rely on the higher dielectric constant of the catalyst and, simultaneously, this type of catalyst has good performance in the degradation of harmful by-products and the degradation of ozone. Therefore, under the photoelectric catalytic system of DBD and a titanium-containing catalyst, researchers can not only conduct in-depth research on a single type of catalyst, but also combine different types of catalyst. In this way, the advantages of different types of catalyst in the DBD system can be maximized; while researchers maximize the degradation efficiency of VOCs, they also need to consider the degradation of harmful by-products and ozone.

\subsection{Future Prospects}

The combination of DBD with titanium-containing catalysts has great advantages in the degradation of VOCs, because it has a certain role, not only in electrocatalysis but also in photocatalysis. Most scholars' research in this area mainly relies on changing the inherent properties of catalysts to achieve the degradation of VOCs. However, the research in this area has been relatively mature. We believe that this field can be further studied in the future through the combination of different types of material and the increase of the light energy released by the discharge by changing the reactor structure. (1) Combining different types of catalyst refers to combining two types of material with different properties to maximize the properties of the two materials. For example, the sol-gelling material can be coated on the molecular sieve material. The coating material has photoelectric catalytic properties. On the other hand, the molecular sieve material can increase the contact area between the coating material and the VOCs, so that the two materials can play the greatest role, and the effect of one plus one is greater than two. (2) In terms of changing the structure of the reactor to increase the light energy released by the discharge, the light energy can be retained and the energy loss caused by the light energy escape can be reduced by changing the light reflecting ability of the barrier dielectric material and the electrode material of the reactor. We believe that these research directions will definitely become research hotspots, and we firmly believe that more and more scholars will be interested in these research directions in the future. 


\section{Conclusions}

This paper conducts a bibliometric analysis of 1181 academic papers related to "application of plasma in the field of VOCs" from 1997 to 2021 and draws the following conclusions: (1) Articles in this field have been on the rise since they first appeared in 1992. Especially in recent years, they have become a research hotspot among scholars; (2) From the analysis of national and institutional data, China and its corresponding affiliated institutions have a much higher number of publications than other countries and regions, indicating that China has a leading position in the research field. Although the United States, France, and Japan have less research than China, they also have great influence; (3) From the perspective of journals and disciplines, research in this field is mainly focused in the discipline of engineering, chemistry, physics, environment, and other disciplines and journals, accounting for nearly 70\%; (4) Through the analysis of the author's keywords in the articles, it can be found that high-frequency keywords include "non-thermal plasma", "dielectric barrier discharge", "toluene", "ozone", "catalyst", and " $\mathrm{TiO}_{2}$ ". It shows that the research hotspot in this field is the catalytic degradation of VOCs in the cooperation of low-temperature plasma of dielectric barrier discharge and catalysts. The high frequency of $\mathrm{TiO}_{2}$ catalysts illustrates the research interest of titanium-containing catalysts in this field; the cluster map of the authors' keywords also proves this point. This article also reviewed the hotspots through keyword analysis and summarized and analyzed related research. It was found that plasma is the most widely used in the field of VOCs; researchers continue to optimize specific processes and catalysts, making the research in this field more forward-looking.

Author Contributions: The study was conceptualized, designed, and coordinated by Y.X. and W.Z. and Y.X. was the principal investigator. W.Z. prepared the draft article. H.Z. (Hui Zhang) and J.W. performed the statistical analysis. The manuscript was written by Y.X., W.Z., H.Z. (Hui Zhang), J.W., H.Z. (Hongshuo Zhang), Z.G. and H.J., while all contributing authors contributed paper revisions under the mentorship of W.S. All authors have read and agreed to the published version of the manuscript.

Funding: This research was funded by the National Natural Science Foundation of China (grant no. 51770438), Beijing Science and Technology Planning Project (grant no. Z191100009119008), the National Science Foundation for Young Scientists of China (grant no. 21707007), the Key Science and Technology Planning Project of HBIS Group Co., Ltd. (grant no. HG2020204-2), and Beijing Nova Program (grant no. Z171100001117084).

Institutional Review Board Statement: "Not applicable" for studies not involving humans or animals.

Informed Consent Statement: “Not applicable." for studies not involving humans or animals.

Data Availability Statement: Data are available in the main text.

Acknowledgments: The authors wish to acknowledge the China National Funds for Distinguished Young Scientists, National Natural Science Foundation of China, and Beijing Science and Technology Project for their financial and logistical contribution to this work. In addition, we would like to thank Yuhshan Ho, who taught us all the analytical skills required for this study.

Conflicts of Interest: The authors declare no conflict of interest.

\section{References}

1. Ousmane, M.; Liotta, L.F.; Carlo, G.D.; Pantaleo, G.; Venezia, A.M.; Deganello, G.; Retailleau, L.; Boreave, A.; Giroir-Fendler, A. Supported Au catalysts for low-temperature abatement of propene and toluene, as model VOCs: Support effect. Appl. Catal. B Environ. 2011, 101, 629-637. [CrossRef]

2. Zhang, L.; Peng, Y.; Zhang, J.; Chen, L.; Meng, X.; Xiao, F.-S. Adsorptive and catalytic properties in the removal of volatile organic compounds over zeolite-based materials. Chin. J. Catal. 2016, 37, 800-809. [CrossRef]

3. Liotta, L.F. Catalytic oxidation of volatile organic compounds on supported noble metals. Appl. Catal. B Environ. 2010, 100, 403-412. [CrossRef]

4. Magulova, K.; Priceputu, A. Global monitoring plan for persistent organic pollutants (POPs) under the Stockholm Convention: Triggering, streamlining and catalyzing global POPs monitoring. Environ. Pollut. 2016, 217, 82-84. [CrossRef] [PubMed] 
5. Neyts, E.C.; Ostrikov, K.K.; Sunkara, M.K.; Bogaerts, A. Plasma Catalysis: Synergistic Effects at the Nanoscale. Chem. Rev. 2015, 115, 13408-13446. [CrossRef] [PubMed]

6. Whitehead, J.C. Plasma-catalysis: The known knowns, the known unknowns and the unknown unknowns. J. Phys. D Appl. Phys. 2016, 49, 243001. [CrossRef]

7. Gomez, E.; Rani, D.A.; Cheeseman, C.R.; Deegan, D.; Wise, M.; Boccaccini, A.R. Thermal plasma technology for the treatment of wastes: A critical review. J. Hazard. Mater. 2009, 161, 614-626. [CrossRef] [PubMed]

8. Hayyan, M.; Hashim, M.A.; AlNashef, I.M. Superoxide Ion: Generation and Chemical Implications. Chem. Rev. 2016, 116, 3029-3085. [CrossRef] [PubMed]

9. Fridman, A.; Nester, S.; Kennedy*, L.A.; Saveliev, A.; Mutaf-Yardimci, O. Gliding arc gas discharge. Prog. Energy Combust. Sci. 1999, 25, 211-231. [CrossRef]

10. Chen, L.; Zhang, X.; Huang, L.; Lei, L. Application of in-plasma catalysis and post-plasma catalysis for methane partial oxidation to methanol over a Fe2O3-CuO/ $\gamma-\mathrm{Al} 2 \mathrm{O} 3$ catalyst. J. Nat. Gas. Chem. 2010, 19, 628-637. [CrossRef]

11. Shou, T.; Li, Y.; Bernards, M.T.; Becco, C.; Cao, G.; Shi, Y.; He, Y. Degradation of gas-phase o-xylene via combined non-thermal plasma and Fe doped LaMnO3 catalysts: Byproduct control. J. Hazard. Mater. 2020, 387, 121750. [CrossRef] [PubMed]

12. Aizawa, H.; Kusakari, S.-i.; Yamada, K.; Noda, K.; Habe, H. Development of Organic Gas Sensor Using Quartz Crystal Microbalance Coated with Plasma-polymerized Films. Sens. Mater. 2020, 32, 1123-1131. [CrossRef]

13. Andreeva, N.; Ishizaki, T.; Baroch, P.; Saito, N. High sensitive detection of volatile organic compounds using superhydrophobic quartz crystal microbalance. Sens. Actuators B Chem. 2012, 164, 15-21. [CrossRef]

14. Dobslaw, D.; Schöller, J.; Krivak, D.; Helbich, S.; Engesser, K.-H. Performance of different biological waste air purification processes in treatment of a waste gas mix containing tert-butyl alcohol and acetone: A comparative study. Chem. Eng. J. 2019, 355, 572-585. [CrossRef]

15. Guo, J.; Lin, C.; Jiang, C.; Zhang, P. Review on noble metal-based catalysts for formaldehyde oxidation at room temperature. Appl. Surf. Sci. 2019, 475, 237-255. [CrossRef]

16. Jiang, N.; Zhao, Y.; Shang, K.; Lu, N.; Li, J.; Wu, Y. Degradation of toluene by pulse-modulated multistage DBD plasma: Key parameters optimization through response surface methodology (RSM) and degradation pathway analysis. J. Hazard. Mater. 2020, 393, 122365. [CrossRef]

17. Kamal, M.S.; Razzak, S.A.; Hossain, M.M. Catalytic oxidation of volatile organic compounds (VOCs)—A review. Atmos. Environ. 2016, 140, 117-134. [CrossRef]

18. Lee, J.E.; Ok, Y.S.; Tsang, D.C.W.; Song, J.; Jung, S.C.; Park, Y.K. Recent advances in volatile organic compounds abatement by catalysis and catalytic hybrid processes: A critical review. Sci. Total Environ. 2020, 719, 137405. [CrossRef]

19. Li, S.; Dang, X.; Yu, X.; Abbas, G.; Zhang, Q.; Cao, L. The application of dielectric barrier discharge non-thermal plasma in VOCs abatement: A review. Chem. Eng. J. 2020, 388, 124275. [CrossRef]

20. Rodriguez Castillo, A.-S.; Biard, P.-F.; Guihéneuf, S.; Paquin, L.; Amrane, A.; Couvert, A. Assessment of VOC absorption in hydrophobic ionic liquids: Measurement of partition and diffusion coefficients and simulation of a packed column. Chem. Eng. J. 2019, 360, 1416-1426. [CrossRef]

21. Yang, C.; Miao, G.; Pi, Y.; Xia, Q.; Wu, J.; Li, Z.; Xiao, J. Abatement of various types of VOCs by adsorption/catalytic oxidation: A review. Chem. Eng. J. 2019, 370, 1128-1153. [CrossRef]

22. Zou, W.; Gao, B.; Ok, Y.S.; Dong, L. Integrated adsorption and photocatalytic degradation of volatile organic compounds (VOCs) using carbon-based nanocomposites: A critical review. Chemosphere 2019, 218, 845-859. [CrossRef] [PubMed]

23. Xing, Y.; Zhang, H.; Su, W.; Wang, Q.; Yu, H.; Wang, J.; Li, R.; Cai, C.; Ma, Z. The bibliometric analysis and review of dioxin in waste incineration and steel sintering. Environ. Sci. Pollut. Res. Int. 2019, 26, 35687-35703. [CrossRef] [PubMed]

24. Xing, Y.; Ma, Z.; Su, W.; Wang, Q.; Wang, X.; Zhang, H. Analysis of Research Status of CO2 Conversion Technology Based on Bibliometrics. Catalysts 2020, 10, 370. [CrossRef]

25. Xing, Y.; Guo, Z.; Su, W.; Wen, W.; Wang, X.; Zhang, H. A review of the hot spot analysis and the research status of single-atom catalysis based on the bibliometric analysis. New J. Chem. 2021, 45, 4253-4269. [CrossRef]

26. Su, W.; Zhang, H.; Xing, Y.; Li, X.; Wang, J.; Cai, C. A Bibliometric Analysis and Review of Supercritical Fluids for the Synthesis of Nanomaterials. Nanomaterials 2021, 11, 336. [CrossRef] [PubMed]

27. Li, X.; Wang, L.; Su, W.; Xing, Y. A review of the research status of CO2 photocatalytic conversion technology based on bibliometrics. New J. Chem. 2021, 45, 2315-2325. [CrossRef]

28. Lauritsen, F.R.; Kotiaho, T.; Choudhury, T.K.; Cooks, R.G. Direct Detection and Identification of Volatile Organic Compounds Dissolved in Organic Solvents by Reversed-Phase Memberane Introduction Tandem Mass Spectrometry. Anal. Chem. 1992, 64, 1205-1211. [CrossRef]

29. Feng, F.; Zheng, Y.; Shen, X.; Zheng, Q.; Dai, S.; Zhang, X.; Huang, Y.; Liu, Z.; Yan, K. Characteristics of back corona discharge in a honeycomb catalyst and its application for treatment of volatile organic compounds. Environ. Sci. Technol. 2015, 49, 6831-6837. [CrossRef]

30. Bo, Z.; Yang, S.; Kong, J.; Zhu, J.; Wang, Y.; Yang, H.; Li, X.; Yan, J.; Cen, K.; Tu, X. Solar-Enhanced Plasma-Catalytic Oxidation of Toluene over a Bifunctional Graphene Fin Foam Decorated with Nanofin-like MnO2. ACS Catal. 2020, 10, 4420-4432. [CrossRef]

31. Chen, J.; Yang, J.; Pan, H.; Su, Q.; Liu, Y.; Shi, Y. Abatement of malodorants from pesticide factory in dielectric barrier discharges. J. Hazard. Mater. 2010, 177, 908-913. [CrossRef] [PubMed] 
32. Shou, T.; Xu, N.; Li, Y.; Sun, G.; Bernards, M.T.; Shi, Y.; He, Y. Mechanisms of Xylene Isomer Oxidation by Non-thermal Plasma via Paired Experiments and Simulations. Plasma Chem. Plasma Processing 2019, 39, 863-876. [CrossRef]

33. Jiang, N.; Qiu, C.; Guo, L.; Shang, K.; Lu, N.; Li, J.; Wu, Y. Post Plasma-Catalysis of Low Concentration VOC Over AluminaSupported Silver Catalysts in a Surface/Packed-Bed Hybrid Discharge Reactor. Water Air Soil Pollut. 2017, 228, 113. [CrossRef]

34. Shang, K.; Ren, J.; Zhang, Q.; Lu, N.; Jiang, N.; Li, J. Successive treatment of benzene and derived byproducts by a novel plasma catalysis-adsorption process. J. Environ. Chem. Eng. 2021, 9, 10576. [CrossRef]

35. Tang, S.; Lu, N.; Li, J.; Shang, K.; Wu, Y. Improved phenol decomposition and simultaneous regeneration of granular activated carbon by the addition of a titanium dioxide catalyst under a dielectric barrier discharge plasma. Carbon 2013, 53, 380-390. [CrossRef]

36. Xu, X.; Wu, J.; Xu, W.; He, M.; Fu, M.; Chen, L.; Zhu, A.; Ye, D. High-efficiency non-thermal plasma-catalysis of cobalt incorporated mesoporous MCM-41 for toluene removal. Catal. Today 2017, 281, 527-533. [CrossRef]

37. Gubal, A.; Chuchina, V.; Ivanenko, N.; Qian, R.; Solovyev, N.; Ganeev, A. Microsecond pulsed glow discharge in copper hollow cathode reveals a new approach to ionization and determination of volatile organic compounds. Spectrochim. Acta Part B At. Spectrosc. 2020, 173, 105986. [CrossRef]

38. Tong, B.; Meng, G.; Deng, Z.; Horprathum, M.; Klamchuen, A.; Fang, X. Surface oxygen vacancy defect engineering of pCuAlO2via Ar\&H2 plasma treatment for enhancing VOCs sensing performances. Chem. Commun. 2019, 55, 11691-11694. [CrossRef]

39. Mei, D.; Duan, G.; Fu, J.; Liu, S.; Zhou, R.; Zhou, R.; Fang, Z.; Cullen, P.J.; Ostrikov, K. $\mathrm{CO}_{2}$ reforming of CH4 in single and double dielectric barrier discharge reactors: Comparison of discharge characteristics and product distribution. J. CO2 Util. 2021, 53, 101703. [CrossRef]

40. Wang, J.; Cheng, S.; Liu, N.; Lu, N.; Shang, K.; Jiang, N.; Li, J.; Wu, Y. Degradation of toluene by tube-tube coaxial dielectric barrier discharge: Power characteristics and power factor optimization. Environ. Technol. 2021, 1-14. [CrossRef]

41. Qin, C.; Guo, H.; Liu, P.; Bai, W.; Huang, J.; Huang, X.; Dang, X.; Yan, D. Toluene abatement through adsorption and plasma oxidation using ZSM-5 mixed with $\gamma$-Al2O3, TiO2 or BaTiO3. J. Ind. Eng. Chem. 2018, 63, 449-455. [CrossRef]

42. Jiang, N.; Qiu, C.; Guo, L.; Shang, K.; Lu, N.; Li, J.; Zhang, Y.; Wu, Y. Plasma-catalytic destruction of xylene over Ag-Mn mixed oxides in a pulsed sliding discharge reactor. J. Hazard. Mater. 2019, 369, 611-620. [CrossRef] [PubMed]

43. Xu, W.; Lin, K.; Ye, D.; Jiang, X.; Liu, J.; Chen, Y. Performance of Toluene Removal in a Nonthermal Plasma Catalysis System over Flake-Like HZSM-5 Zeolite with Tunable Pore Size and Evaluation of Its Byproducts. Nanomaterials 2019, 9, 290. [CrossRef] [PubMed]

44. Yao, X.; Jiang, N.; Li, J.; Lu, N.; Shang, K.; Wu, Y. An improved corona discharge ignited by oxide cathodes with high secondary electron emission for toluene degradation. Chem. Eng. J. 2019, 362, 339-348. [CrossRef]

45. Jahanmiri, A.; Rahimpour, M.R.; Mohamadzadeh Shirazi, M.; Hooshmand, N.; Taghvaei, H. Naphtha cracking through a pulsed DBD plasma reactor: Effect of applied voltage, pulse repetition frequency and electrode material. Chem. Eng. J. 2012, 191, 416-425. [CrossRef]

46. Li, S.; Yu, X.; Dang, X.; Guo, H.; Liu, P.; Qin, C. Using non-thermal plasma for decomposition of toluene adsorbed on $\gamma$-Al2O3 and ZSM-5: Configuration and optimization of a double dielectric barrier discharge reactor. Chem. Eng. J. 2019, $375,122027$. [CrossRef]

47. Jiang, N.; Lu, N.; Shang, K.; Li, J.; Wu, Y. Effects of electrode geometry on the performance of dielectric barrier/packed-bed discharge plasmas in benzene degradation. J. Hazard. Mater. 2013, 262, 387-393. [CrossRef]

48. Mustafa, M.F.; Fu, X.; Lu, W.; Liu, Y.; Abbas, Y.; Wang, H.; Arslan, M.T. Application of non-thermal plasma technology on fugitive methane destruction: Configuration and optimization of double dielectric barrier discharge reactor. J. Clean. Prod. 2018, 174, 670-677. [CrossRef]

49. Ojah, N.; Thakur, S.; Gogoi, D.; Ahmed, G.A.; Mandal, M.; Doley, R.; Choudhury, A.J. Effects of Dielectric Barrier Discharge Plasma on Physicochemical Characteristics, Mechanical Properties and Biocompatibility of Silk/PVA Nanofibers. Plasma Chem. Plasma Processing 2021, 1-16. [CrossRef]

50. Jin, S.; Li, Z.; Xian, Y.; Nie, L.; Lu, X. A non-equal gap distance dielectric barrier discharge: Between cone-shape and cylinder-shape electrodes. High Volt. 2021. [CrossRef]

51. Jiang, N.; Qiu, C.; Guo, L.; Shang, K.; Lu, N.; Li, J.; Wu, Y. Improved Performance for Toluene Abatement in a Continuous-Flow Pulsed Sliding Discharge Reactor Based on Three-Electrode Configuration. Plasma Chem. Plasma Processing 2018, 39, 227-240. [CrossRef]

52. Bahri, M.; Haghighat, F.; Rohani, S.; Kazemian, H. Impact of design parameters on the performance of non-thermal plasma air purification system. Chem. Eng. J. 2016, 302, 204-212. [CrossRef]

53. Wang, B.; Yan, W.; Ge, W.; Duan, X. Methane conversion into higher hydrocarbons with dielectric barrier discharge micro-plasma reactor. J. Energy Chem. 2013, 22, 876-882. [CrossRef]

54. Lee, B.; Kim, D.-W.; Park, D.-W. Dielectric barrier discharge reactor with the segmented electrodes for decomposition of toluene adsorbed on bare-zeolite. Chem. Eng. J. 2019, 357, 188-197. [CrossRef]

55. Guo, T.; Cheng, G.; Tan, G.; Xu, L.; Huang, Z.; Cheng, P.; Zhou, Z. Real-time analysis of intermediate products from non-thermal plasma degradation of ethyl acetate in air using PTR-MS: Performance evaluation and mechanism study. Chemosphere 2021, 264, 128430. [CrossRef] 
56. Holzer, F.; Roland, U.; Kopinke, F.-D. Combination of non-thermal plasma and heterogeneous catalysis for oxidation of volatile organic compounds Part 1. Accessibility of the intra-particle volume. Appl. Catal. B Environ. 2002, 38, 163-181. [CrossRef]

57. Roland, U.; Holzer, F.; Kopinke, F.D. Combination of non-thermal plasma and heterogeneous catalysis for oxidation of volatile organic compounds Part 2. Ozone decomposition and deactivation of g-Al2O3. Appl. Catal. B Environ. 2005, 58, 217-226. [CrossRef]

58. Roland, U.; Holzer, F.; Pöppl, A.; Kopinke, F.D. Combination of non-thermal plasma and heterogeneous catalysis for oxidation of volatile organic compounds Part 3. Electron paramagnetic resonance (EPR) studies of plasma-treated porous alumina. Appl. Catal. B Environ. 2005, 58, 227-234. [CrossRef]

59. Qin, C.; Guo, H.; Bai, W.; Huang, J.; Huang, X.; Dang, X.; Yan, D. Kinetics study on non-thermal plasma mineralization of adsorbed toluene over gamma-Al2O3 hybrid with zeolite. J. Hazard. Mater. 2019, 369, 430-438. [CrossRef]

60. Byeon, J.H.; Park, J.H.; Jo, Y.S.; Yoon, K.Y.; Hwang, J. Removal of gaseous toluene and submicron aerosol particles using a dielectric barrier discharge reactor. J. Hazard. Mater. 2010, 175, 417-422. [CrossRef]

61. Gandhi, M.S.; Mok, Y.S. Decomposition of trifluoromethane in a dielectric barrier discharge non-thermal plasma reactor. J. Environ. Sci. 2012, 24, 1234-1239. [CrossRef]

62. Lu, W.; Abbas, Y.; Mustafa, M.F.; Pan, C.; Wang, H. A review on application of dielectric barrier discharge plasma technology on the abatement of volatile organic compounds. Front. Environ. Sci. Eng. 2019, 13, 30. [CrossRef]

63. Wang, C.; Zhang, G.; Wang, X. Comparisons of discharge characteristics of a dielectric barrier discharge with different electrode structures. Vacuum 2012, 86, 960-964. [CrossRef]

64. Li, Y.; Yang, D.-Z.; Qiao, J.-J.; Zhang, L.; Wang, W.-Z.; Zhao, Z.-L.; Zhou, X.-F.; Yuan, H.; Wang, W.-C. The dynamic evolution and interaction with dielectric material of the discharge in packed bed reactor. Plasma Sources Sci. Technol. 2020, 29, 055004. [CrossRef]

65. Kundu, S.K.; Kennedy, E.M.; Gaikwad, V.V.; Molloy, T.S.; Dlugogorski, B.Z. Experimental investigation of alumina and quartz as dielectrics for a cylindrical double dielectric barrier discharge reactor in argon diluted methane plasma. Chem. Eng. J. 2012, 180, 178-189. [CrossRef]

66. Khoja, A.H.; Tahir, M.; Amin, N.A.S. Dry reforming of methane using different dielectric materials and DBD plasma reactor configurations. Energy Convers. Manag. 2017, 144, 262-274. [CrossRef]

67. Kraus, M.; Eliasson, B.; Kogelschatz, U.; Wokaun, A. CO2 reforming of methane by the combination of dielectric-barrier discharges and catalysis. Phys. Chem. Chem. Phys. 2001, 3, 294-300. [CrossRef]

68. Cheng, Z.; Li, C.; Chen, D.; Chen, J.; Zhang, S.; Ye, J.; Yu, J.; Dionysiou, D.D. A novel array of double dielectric barrier discharge combined with TiCo catalyst to remove high-flow-rate toluene: Performance evaluation and mechanism analysis. Sci. Total Environ. 2019, 692, 940-951. [CrossRef] [PubMed]

69. Liu, J.; Ji, Y.; Zhu, S.; Guo, T.; Xu, L.; Dong, J.; Cheng, P. C-dot doping for enhanced catalytic performance of TiO2/5A for toluene degradation in non-thermal plasma-catalyst system. Environ. Sci. Pollut. Res. Int. 2021, 29, 2480-2492. [CrossRef] [PubMed]

70. Zeng, X.; Li, B.; Liu, R.; Li, X.; Zhu, T. Investigation of promotion effect of Cu doped MnO2 catalysts on ketone-type VOCs degradation in a one-stage plasma-catalysis system. Chem. Eng. J. 2020, 384, 123362. [CrossRef]

71. Gharib-Abou Ghaida, S.; Assadi, A.A.; Costa, G.; Bouzaza, A.; Wolbert, D. Association of surface dielectric barrier discharge and photocatalysis in continuous reactor at pilot scale: Butyraldehyde oxidation, by-products identification and ozone valorization. Chem. Eng. J. 2016, 292, 276-283. [CrossRef]

72. Sivachandiran, L.; Thevenet, F.; Gravejat, P.; Rousseau, A. Isopropanol saturated TiO2 surface regeneration by non-thermal plasma: Influence of air relative humidity. Chem. Eng. J. 2013, 214, 17-26. [CrossRef]

73. Zhang, H.; Li, K.; Sun, T.; Jia, J.; Lou, Z.; Feng, L. Removal of styrene using dielectric barrier discharge plasmas combined with sol-gel prepared $\mathrm{TiO} 2$ coated $\gamma$-Al2O3. Chem. Eng. J. 2014, 241, 92-102. [CrossRef]

74. Wang, J.; Cao, X.; Zhang, R.; Gong, T.; Hou, H.; Chen, S.; Zhang, R. Effect of Water Vapor on Toluene Removal in Catalysis-DBD Plasma Reactors. Plasma Sci. Technol. 2016, 18, 370-375. [CrossRef]

75. Dou, B.; Liu, D.; Zhang, Q.; Zhao, R.; Hao, Q.; Bin, F.; Cao, J. Enhanced removal of toluene by dielectric barrier discharge coupling with Cu-Ce-Zr supported ZSM-5/TiO2/Al2O3. Catal. Commun. 2017, 92, 15-18. [CrossRef]

76. Ye, Z.; Ye, Z.; Nikiforov, A.; Chen, J.; Zhou, W.; Chen, J.; Wang, G.; Zhang, Y. Influence of mixed-phase TiO2 on the activity of adsorption-plasma photocatalysis for total oxidation of toluene. Chem. Eng. J. 2021, 407, 126280. [CrossRef]

77. Kim, H.-H.; Ogata, A.; Futamura, S. Oxygen partial pressure-dependent behavior of various catalysts for the total oxidation of VOCs using cycled system of adsorption and oxygen plasma. Appl. Catal. B Environ. 2008, 79, 356-367. [CrossRef]

78. Yan, Y.; Gao, Y.-N.; Zhang, L.-Y.; Zhang, X.-M.; Zhu, B.; Li, M.; Zhu, Y.-M. Promoting Plasma Photocatalytic Oxidation of Toluene Via the Construction of Porous Ag-CeO2/TiO2 Photocatalyst with Highly Active Ag/oxide Interface. Plasma Chem. Plasma Processing 2020, 41, 335-350. [CrossRef]

79. Li, M.; Li, D.; Zhang, Z.; Ji, C.; Zhou, S.; Guo, W.; Zhao, C.; Liu, F.; Han, F. Study on the performance and mechanism of degradation of toluene with non-thermal plasmas synergized supported $\mathrm{TiO} 2 / \gamma-\mathrm{Al} 2 \mathrm{O} 3$ catalyst. J. Environ. Chem. Eng. 2021, 9 , 105529. [CrossRef]

80. Song, H.; Peng, Y.; Liu, S.; Bai, S.; Hong, X.; Li, J. The Roles of Various Plasma Active Species in Toluene Degradation by Non-thermal Plasma and Plasma Catalysis. Plasma Chem. Plasma Processing 2019, 39, 1469-1482. [CrossRef]

81. Wang, B.; Yao, S.; Peng, Y.; Xu, Y. Toluene removal over TiO2-BaTiO3 catalysts in an atmospheric dielectric barrier discharge. J. Environ. Chem. Eng. 2018, 6, 3819-3826. [CrossRef] 
82. Zhang, H.; Li, K.; Li, L.; Liu, L.; Meng, X.; Sun, T.; Jia, J.; Fan, M. High efficient styrene mineralization through novel NiO-TiO2$\mathrm{Al} 2 \mathrm{O} 3$ packed pre-treatment/treatment/post-treatment dielectric barrier discharge plasma. Chem. Eng. J. 2018, 343, 759-769. [CrossRef]

83. Cimerman, R.; Račková, D.; Hensel, K. Tars removal by non-thermal plasma and plasma catalysis. J. Phys. D Appl. Phys. 2018, 51, 274003. [CrossRef]

84. Zhang, H.; Li, K.; Sun, T.; Jia, J.; Lou, Z.; Yao, S.; Wang, G. The combination effect of dielectric barrier discharge (DBD) and TiO2 catalytic process on styrene removal and the analysis of the by-products and intermediates. Res. Chem. Intermed. 2013, 41, 175-189. [CrossRef]

85. Lu, B.; Zhang, X.; Yu, X.; Feng, T.; Yao, S. Catalytic oxidation of benzene using DBD corona discharges. J. Hazard. Mater. 2006, 137, 633-637. [CrossRef] [PubMed]

86. KARUPPIAH, J.; LINGA REDDY, E.; SIV ACHANDIRAN, L.; KARVEMBU, R.; SUBRAHMANY AM, C. Nonthermal plasma assisted photocatalytic oxidation of dilute benzene. J. Chem. Sci. 2012, 124, 841-845. [CrossRef]

87. Ye, Z.; Wang, C.; Shao, Z.; Ye, Q.; He, Y.; Shi, Y. A novel dielectric barrier discharge reactor with photocatalytic electrode based on sintered metal fibers for abatement of xylene. J. Hazard. Mater. 2012, 241-242, 216-223. [CrossRef] [PubMed]

88. Wu, Z.; Zhu, Z.; Hao, X.; Zhou, W.; Han, J.; Tang, X.; Yao, S.; Zhang, X. Enhanced oxidation of naphthalene using plasma activation of TiO2/diatomite catalyst. J. Hazard. Mater. 2018, 347, 48-57. [CrossRef]

89. Barakat, C.; Gravejat, P.; Guaitella, O.; Thevenet, F.; Rousseau, A. Oxidation of isopropanol and acetone adsorbed on TiO2 under plasma generated ozone flow: Gas phase and adsorbed species monitoring. Appl. Catal. B Environ. 2014, 147, 302-313. [CrossRef]

90. Abou Saoud, W.; Assadi, A.A.; Kane, A.; Jung, A.-V.; Le Cann, P.; Gerard, A.; Bazantay, F.; Bouzaza, A.; Wolbert, D. Integrated process for the removal of indoor VOCs from food industry manufacturing: Elimination of Butane-2,3-dione and Heptan-2-one by cold plasma-photocatalysis combination. J. Photochem. Photobiol. A Chem. 2020, 386, 112071. [CrossRef]

91. Zhang, S.; Wang, W.; Zhang, L.; Zhao, Z.; Yang, D. Nanosecond pulsed dielectric barrier discharge plasma-catalytic removal of HCHO in humid air. Eur. Phys. J. Appl. Phys. 2017, 78, 20803. [CrossRef]

92. Jia, Z.; Vega-Gonzalez, A.; Amar, M.B.; Hassouni, K.; Tieng, S.; Touchard, S.; Kanaev, A.; Duten, X. Acetaldehyde removal using a diphasic process coupling a silver-based nano-structured catalyst and a plasma at atmospheric pressure. Catal. Today 2013, 208, 82-89. [CrossRef]

93. Gandhi, M.S.; Mok, Y.S.; Lee, S.B.; Park, H. Effect of various parameters for butane decomposition under ambient temperature in a dielectric barrier discharge non-thermal plasma reactor. J. Taiwan Inst. Chem. Eng. 2013, 44, 786-794. [CrossRef]

94. Gandhi, M.S.; Mok, Y.S. Non-thermal plasma-catalytic decomposition of volatile organic compounds using alumina supported metal oxide nanoparticles. Surf. Coat. Technol. 2014, 259, 12-19. [CrossRef]

95. Song, H.; Hu, F.; Peng, Y.; Li, K.; Bai, S.; Li, J. Non-thermal plasma catalysis for chlorobenzene removal over CoMn/TiO2 and $\mathrm{CeMn/TiO2:} \mathrm{Synergistic} \mathrm{effect} \mathrm{of} \mathrm{chemical} \mathrm{catalysis} \mathrm{and} \mathrm{dielectric} \mathrm{constant.} \mathrm{Chem.} \mathrm{Eng.} \mathrm{J.} \mathrm{2018,} \mathrm{347,} \mathrm{447-454.} \mathrm{[CrossRef]}$

96. Ghorbani Shahna, F.; Ebrahimi, H.; Jaleh, B.; Bahrami, A. Decomposition of gas-phase chloroform using nanophotocatalyst downstream the novel non-thermal plasma reactor: By-products elimination. Int. J. Environ. Sci. Technol. 2015, 12, 3489-3498. [CrossRef]

97. Jeong, J.G.; Lee, H.S.; Kang, Y.; Lee, K.B.; Yoo, J.W. Toluene decomposition by DBD-type plasma combined with metal oxide catalysts supported on ferroelectric materials. J. Nanosci. Nanotechnol. 2013, 13, 4146-4149. [CrossRef] [PubMed]

98. Jiang, N.; Li, J.; Shang, K.; Lu, N.; Wu, Y. Enhanced Degradation of Benzene in Surface/Packed-Bed Hybrid Discharge System: Optimization of the Reactor Structure and Electrical Parameters. IEEE Trans. Plasma Sci. 2016, 44, 657-664. [CrossRef]

99. Zhu, T.; Wan, Y.; Li, H.; Chen, S.; Fang, Y. VOCs Decomposition via Modified Ferroelectric Packed Bed Dielectric Barrier Discharge Plasma. IEEE Trans. Plasma Sci. 2011, 39, 1695-1700. [CrossRef]

100. Zhu, R.; Mao, Y.; Jiang, L.; Chen, J. Performance of chlorobenzene removal in a nonthermal plasma catalysis reactor and evaluation of its byproducts. Chem. Eng. J. 2015, 279, 463-471. [CrossRef]

101. Wang, H.; Wang, J.; Zhang, L.; Yu, Q.; Chen, Z.; Wu, S. A New Strategy for Improving the Efficiency of Low-temperature Selective Catalytic Reduction of NOx with CH4via the Combination of Non-thermal Plasma and Ag2O/TiO2 Photocatalyst. Chem. Res. Chin. Univ. 2019, 35, 1062-1069. [CrossRef]

102. Wang, X.; Barakat, C.; Jia, Z.; Romanias, M.N.; Thévenet, F.; Rousseau, A. Adsorption of VOCs Is a Key Step in Plasma-Catalyst Coupling: The Case of Acetone onto TiO2 vs. CeO2. Catalysts 2021, 11, 350. [CrossRef]

103. Pangilinan, C.D.C.; Kurniawan, W.; Hinode, H. Effect of MnOx/TiO2Oxidation State on Ozone Concentration in a Nonthermal Plasma-Driven Catalysis Reactor. Ozone: Sci. Eng. 2015, 38, 156-162. [CrossRef]

104. Zhu, B.; Zhang, L.; Yan, Y.; Li, M.; Zhu, Y. Enhancing toluene removal in a plasma photocatalytic system through a black TiO2 photocatalyst. Plasma Sci. Technol. 2019, 21, 115503. [CrossRef]

105. Pangilinan, C.D.C.; Kurniawan, W.; Salim, C.; Hinode, H. Effect of Ag/TiO2 catalyst preparation on gas-phase benzene decomposition using non-thermal plasma driven catalysis under oxygen plasma. React. Kinet. Mech. Catal. 2015, 117, 103-118. [CrossRef]

106. Wei, B.; Chen, Y.; Ye, M.; Shao, Z.; He, Y.; Shi, Y. Enhanced Degradation of Gaseous Xylene Using Surface Acidized TiO2 Catalyst with Non-thermal Plasmas. Plasma Chem. Plasma Processing 2014, 35, 173-186. [CrossRef]

107. Guaitella, O.; Thevenet, F.; Puzenat, E.; Guillard, C.; Rousseau, A. C2H2 oxidation by plasma/TiO2 combination: Influence of the porosity, and photocatalytic mechanisms under plasma exposure. Appl. Catal. B Environ. 2008, 80, 296-305. [CrossRef] 
108. Abedi, K.; Ghorbani-Shahna, F.; Jaleh, B.; Bahrami, A.; Yarahmadi, R.; Haddadi, R.; Gandomi, M. Decomposition of chlorinated volatile organic compounds (CVOCs) using NTP coupled with TiO2/GAC, ZnO/GAC, and TiO2-ZnO/GAC in a plasma-assisted catalysis system. J. Electrost. 2015, 73, 80-88. [CrossRef]

109. Ghorbani Shahna, F.; Bahrami, A.; Alimohammadi, I.; Yarahmadi, R.; Jaleh, B.; Gandomi, M.; Ebrahimi, H.; Ad-Din Abedi, K Chlorobenzene degeradation by non-thermal plasma combined with EG-TiO2/ZnO as a photocatalyst: Effect of photocatalyst on CO2 selectivity and byproducts reduction. J. Hazard. Mater. 2017, 324, 544-553. [CrossRef]

110. Abedi, K.; Ghorbani-Shahna, F.; Bahrami, A.; Jaleh, B.; Yarahmadi, R. Effect of TiO2-ZnO/GAC on by-product distribution of CVOCs decomposition in a NTP-assisted catalysis system. Pol. J. Chem. Technol. 2015, 17, 32-40. [CrossRef]

111. Vega-González, A.; Duten, X.; Sauce, S. Plasma-Catalysis for Volatile Organic Compounds Decomposition: Complexity of the Reaction Pathways during Acetaldehyde Removal. Catalysts 2020, 10, 1146. [CrossRef]

112. Wang, R.; Ren, J.; Wu, J.; Wu, L. Characteristics and mechanism of toluene removal by double dielectric barrier discharge combined with an Fe2O3/TiO2/ $\gamma$-Al2O3 catalyst. RSC Adv. 2020, 10, 41511-41522. [CrossRef]

113. Gao, Y.; Peng, X.; Zhang, Z.; Zhang, W.; Li, H.; Chen, B.; Li, S.; Zhang, Y.; Chi, S. Ternary mixed-oxide synergy effects of nano $\mathrm{TiO} 2-\mathrm{FexOy}-\mathrm{MOk}(\mathrm{M}=\mathrm{Mn}, \mathrm{Ce}, \mathrm{Co})$ on $\alpha$-pinene catalytic oxidation process assisted by nonthermal plasma. Mater. Res. Express 2021, 8, 011509. [CrossRef]

114. Zhu, T.; Li, R.R.; Ma, M.F.; Li, X. Influence of energy efficiency on VOCs decomposition in non-thermal plasma reactor. Int. J. Environ. Sci. Technol. 2017, 14, 1505-1512. [CrossRef]

115. Zhu, T.; Chen, R.; Xia, N.; Li, X.; He, X.; Zhao, W.; Carr, T. Volatile organic compounds emission control in industrial pollution source using plasma technology coupled with F-TiO2/gamma-Al2O3. Environ. Technol. 2015, 36, 1405-1413. [CrossRef] [PubMed]

116. Shayegan, Z.; Lee, C.-S.; Haghighat, F. TiO2 photocatalyst for removal of volatile organic compounds in gas phase-A review. Chem. Eng. J. 2018, 334, 2408-2439. [CrossRef]

117. Shah, K.W.; Li, W. A Review on Catalytic Nanomaterials for Volatile Organic Compounds VOC Removal and Their Applications for Healthy Buildings. Nanomaterials 2019, 9, 910. [CrossRef]

118. Arsac, F.; Bianchi, D.; Chovelon, J.M.; Ferronato, C.; Herrmann, J.M. Experimental microkinetic approach of the photocatalytic oxidation of isopropyl alcohol on $\mathrm{TiO} 2$. Part 2. From the surface elementary steps to the rates of oxidation of the $\mathrm{C} 3 \mathrm{HxO}$ species. J. Phys. Chem. A 2006, 110, 4213-4222. [CrossRef]

119. Arsac, F.; Bianchi, D.; Chovelon, J.M.; Ferronato, C.; Herrmann, J.M. Experimental Microkinetic Approach of the Photocatalytic Oxidation of Isopropyl Alcohol on TiO2. Part 1. Surface Elementary Steps Involving Gaseous and Adsorbed C3HxO Species. J. Phys. Chem. A 2006, 110, 4202-4212. [CrossRef] 